\title{
Contexto geológico, estudos isotópicos (C, O e Pb) e associação metálica do depósito aurífero Tocantinzinho, domínio Tapajós, Província Tapajós-Parima
}

\author{
Geological setting, isotope studies $(C, O$ and $P b)$ and associated metals in the \\ Tocantinzinho gold deposit, Tapajós domain, Tapajós-Parima Province
}

\begin{abstract}
Raimundo Netuno Nobre Villas ${ }^{1}$, Érika Suellen Barbosa Santiago², Marília Portela Castilho²
1Universidade Federal do Pará - UFPA, Rua Augusto Corrêa 1, CEP 66075-110, Belém, PA, BR (netuno@ufpa.br)

2Programa de Pós-graduação em Geologia e Geoquímica, Instituto de Geociências, Universidade Federal do Pará - UFPA, Belém, PA, BR (esbsantiago@gmail.com; castilho.marilia@hotmail.com)
\end{abstract}

Recebido em 05 de julho de 2012; aceito em 19 de dezembro de 2012

\begin{abstract}
Resumo
O depósito Tocantinzinho, localizado em um lineamento de direção NW-SE, a SW de Itaituba (PA), é atualmente o maior depósito aurífero conhecido na Província Tapajós. Está hospedado no granito homônimo, essencialmente isótropo, no qual dominam rochas sieno e monzograníticas, que foram fraca a moderadamente alteradas por fluidos hidrotermais. Microclinização (mais precoce), cloritização, sericitização, silicificação e carbonatação (mais tardia) são os mais importantes tipos de alteração. O principal estágio de mineralização é contemporâneo à sericitização/silicificação e é representado por vênulas com sulfetos (pirita \pm calcopirita \pm galena \pm esfalerita) e ouro associado, as quais mostram localmente trama stockwork. Além de teores expressivos de $\mathrm{Cu}, \mathrm{Pb}$ e $\mathrm{Zn}$, são anômalos, em algumas amostras, os de As, Bi e Mo. A relação dos teores do Au com os dos metais-base é aleatória e as razões $\mathrm{Au} / \mathrm{Ag}$ variam de 0,05 a 5,0. O Au é mais enriquecido nas porções com maior abundância de sulfetos de metais-base, embora ocorra principalmente incluso na pirita. Monocristais de zircão, extraídos do granito Tocantinzinho, forneceram idade $\mathrm{Pb}-\mathrm{Pb}$ média de $1982 \pm 8$ Ma, permitindo interpretá-lo como uma manifestação magmática precoce do arco Creporizão. Valores de $\delta^{13} \mathrm{C}_{\mathrm{PDB}} \mathrm{em}$ calcita do estágio de carbonatação, dominantemente entre -3,45 e -2,29\%, são compatíveis com fonte crustal profunda, quiçá carbonatítica, enquanto os de $\delta^{18} \mathrm{O}_{\text {SMOW }}(+5,97 \mathrm{a}+14,10 \%)$ indicam forte contribuição magmática, ainda que mascarada por influxo de águas provavelmente superficiais. Estudos de inclusões fluidas em andamento revelam a presença de fluidos aquocarbônicos, cujo $\mathrm{CO}_{2}$ poderia ter estado dissolvido no magma granítico em vez de ser relacionado à zona de cisalhamento. Os dados até aqui disponíveis permitem classificar o depósito aurífero Tocantinzinho como do tipo relacionado à intrusão.
\end{abstract}

Palavras-chave: Província Tapajós; Granitoides; Mineralização aurífera; Suíte metálica; Isótopos radiogênicos e estáveis.

\begin{abstract}
The Tocantinzinho ore deposit is located along a NW-SE-trending lineament, southwestern of Itaituba (Pará, Brazil), and is the largest known gold deposit of the Tapajós Province. The host Tocantinzinho granite is essentially isotropic and dominated by syenogranites and monzogranites that have been weakly to moderately altered by hydrothermal fluids. Microclinization (earliest), chloritization, sericitization, silicification and carbonatization (latest) are the main types of alteration. Most mineralization was contemporaneous with the sericitization/silicification and is represented by sulfide- and gold-bearing veinlets which locally occur as stockwork. Pyrite, chalcopyrite, sphalerite and galena are the most common sulfides. Among the ore metals, $\mathrm{Cu}, \mathrm{Pb}$ and $\mathrm{Zn}$ present the highest contents, but Mo, As and $\mathrm{Bi}$ locally show anomalous concentrations. The relationship of $\mathrm{Au}$ with $\mathrm{Cu}, \mathrm{Pb}$ or $\mathrm{Zn}$ is at random and the $\mathrm{Au} / \mathrm{Ag}$ ratios range from 0.05 to 0.5 . The higher the sulfide contents, the higher the Au concentrations, though it occurs mainly included in pyrite. Zircon monocrystals from the Tocantinzinho granite yielded an average $\mathrm{Pb}-\mathrm{Pb}$ age of $1982 \pm 8 \mathrm{Ma}$ and may represent an earlier event of the Creporizão magmatic arc. $\delta^{13} \mathrm{C}_{\mathrm{PDB}}$ values for calcite from the carbonatization stage fall dominantly between -3.45 and $-2.29 \%$, being compatible with a deep crustal source that may include carbonatite reservoirs. In turn, $\delta^{18} \mathrm{O}_{\text {SMOW }}$ values vary from +5.97 to $+14.10 \%$, being indicative of magmatic derivation, although the less positive values suggest contribution from surficial waters. Unpublished fluid inclusion study reveals the presence of aquo-carbonic fluids, whose $\mathrm{CO}_{2}$ could have been dissolved in the granitic magma rather than being related to the shear zone. The available data allow the Tocantinzinho deposit to be classified as a granite-hosted, intrusion-related gold deposit.
\end{abstract}

Keywords: Tapajós Province; Granitoids; Gold mineralization; Metallic suite; Radiogenic and stable isotopes. 


\section{INTRODUÇÃO}

O depósito Tocantinzinho está situado às margens do rio Tocantins, afluente do rio Jamanxim/Tapajós, a aproximadamente $200 \mathrm{~km}$ a sudoeste da cidade de Itaituba, estado do Pará (Figura 1). A atual área do depósito, um antigo garimpo, passou a ser sistematicamente prospectada para ouro primário a partir do final da década de 1990 com trabalhos da empresa Minera Altoro, que definiu importantes anomalias em uma faixa de aproximadamente $400 \times 1.000 \mathrm{~m}$. Negociado, em seguida, com a Solitario Resources Corporation, o projeto foi, devido à baixa cotação do ouro no mercado internacional em 2000, descontinuado e retomado em 2003/2004 pela Jaguar Resources do Brasil, subsidiária da Brazauros Resources Corporation, que intensificou o programa de exploração. A crise econômica mundial de 2008, no entanto, abalou o empreendimento, e os direitos minerários foram adquiridos pela mineradora Eldorado Gold, do Canadá, cuja subsidiária brasileira Unamgen Mineração e Metalurgia Ltda. avançou nas atividades exploratórias e deu início a projetos visando à etapa de lavra. Até hoje, cerca de 160 furos de sondagem já foram executados e aproximadamente $45.000 \mathrm{~m}$ de testemunhos amostrados, o que permitiu delimitar um corpo mineralizado com dimensões de $700 \mathrm{~m}$ (comprimento) x $150 \mathrm{~m}$ (largura) x $300 \mathrm{~m}$ (profundidade) e teor médio de $1,25 \mathrm{~g} / \mathrm{t} \mathrm{Au}$.
As reservas medidas são de $49 \mathrm{Mt}$ de minério ou pouco mais de 61 t de ouro (Juras, Gregersen, Alexander, 2011), o que torna o Tocantinzinho o maior depósito aurífero conhecido na Província Tapajós, com tempo de vida estimado em 11 anos para a produção anual de minério prevista.

O presente estudo visou a contribuir com o entendimento da formação do depósito Tocantinzinho e se apoiou em dados geológicos, petrográficos, químicos e isotópicos, que possibilitaram descrever as rochas mineralizadas e os tipos de alteração hidrotermal, analisar a relação do ouro com outros metais e semimetais, datar o granito hospedeiro e avaliar as fontes de $\mathrm{C}$ e $\mathrm{O}$ durante o estágio da carbonatação.

\section{MATERIAIS E PROCEDIMENTOS METODOLÓGICOS}

As análises químicas foram realizadas por Inductively Coupled Plasma Mass Spectrometry (ICP-MS) em 42 amostras de testemunhos de sondagem na Acme Analytical Labo ratories Ltd. (Vancouver, Canadá). Por terem sido as amostras pulverizadas em moinhos de vídia, foram descartados os dados referentes ao $\mathrm{W}$ e Ni. As determinações isotópicas de $\mathrm{C}$ e $\mathrm{O}$ em calcita foram conduzidas no Laboratório de Isótopos Estáveis da Universidade Federal de Pernambuco
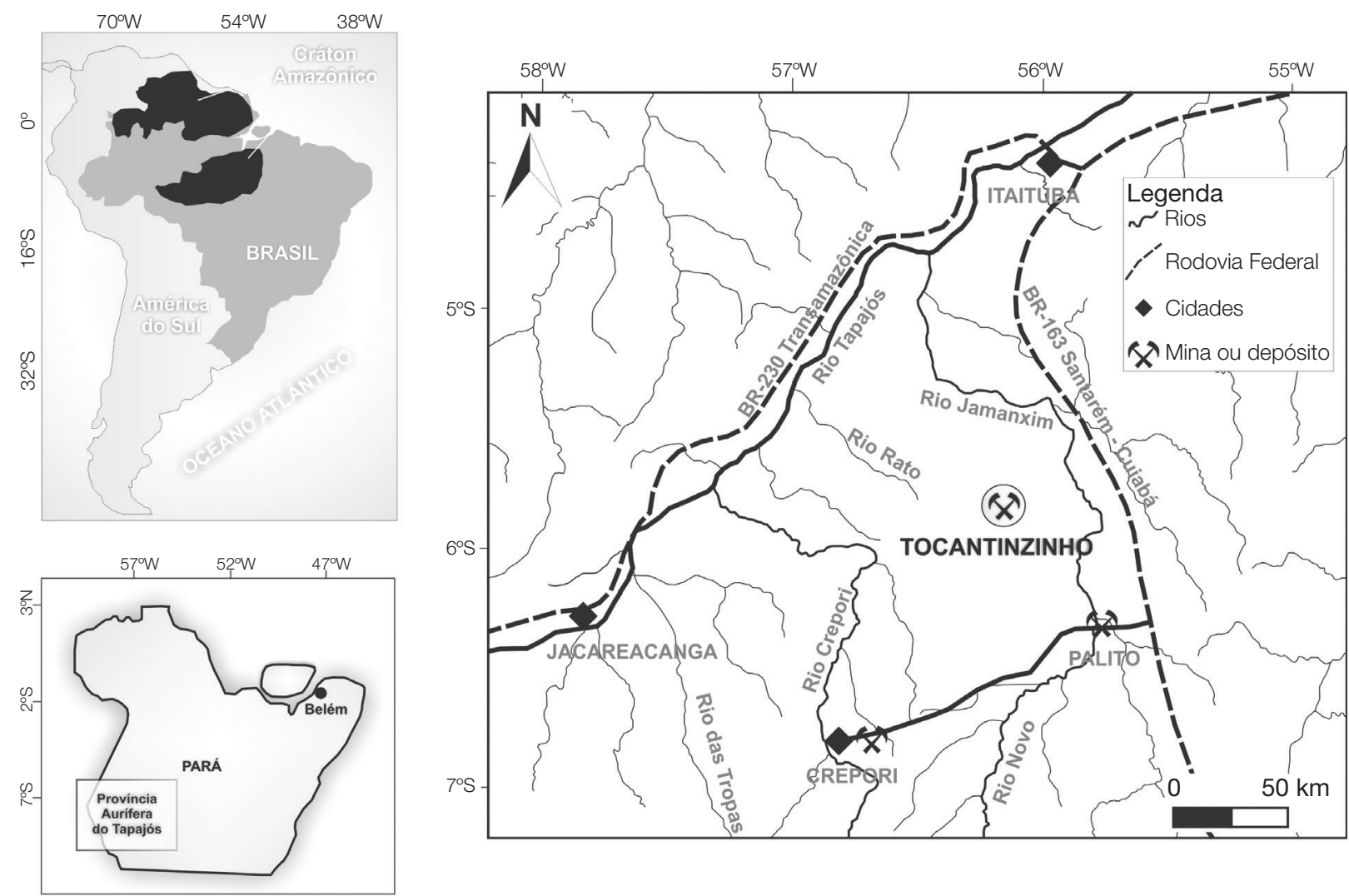

Figura 1. Mapa de localização do depósito Tocantinzinho, sudoeste do Estado do Pará. 
(LABISE-UFPE) em espectrômetro de massa SIRA II, seguindo-se os procedimentos analíticos de rotina deste laboratório e que constam em Nogueira et al. (2007). As datações geocronológicas foram realizadas em espectrômetro de massa Finningan MAT 262 do Laboratório de Geologia Isotópica (Pará-Iso) do Instituto de Geociências da Universidade Federal do Pará (IG-UFPA) pelo método Pb-Pb em monocristais de zircão e partículas de ouro, obedecendo-se aos procedimentos implantados neste laboratório e descritos, respectivamente, em Costi, Dall'Agnol e Moura (2000) e Galarza, Krimsky e Rolando (2004). Algumas amostras foram metalizadas com carbono e examinadas em microscópio eletrônico de varredura LEO 1430 acoplado a espectrômetro de dispersão de energia do Laboratório de Microscopia Eletrônica de Varredura (LABMEV) do IG-UFPA.

\section{PROVÍNCIA AURÍFERA DO TAPAJÓS}

A Província Aurífera do Tapajós (PAT) está localizada na porção centro-sul do Cráton Amazônico e tem seus limites coincidentes com o domínio Tapajós, que integra, junto aos domínios Uaimiri, Parima e Alta Floresta, a faixa orogênica Tapajós-Parima (Santos et al., 2000) ou VentuariTapajós (Tassinari e Macambira, 2004). Limitada a leste pela Província Amazônia Central, ao norte pela bacia do Amazonas, e ao sul e oeste pela bacia do Cachimbo, a PAT abrange parte do sudoeste do estado do Pará e uma pequena parte do sudeste do estado do Amazonas (Figura 2), e apresenta algumas feições geológicas, estruturais e metalogenéticas semelhantes a outras províncias auríferas como Peixoto de Azevedo (MT) e Parima (RR).

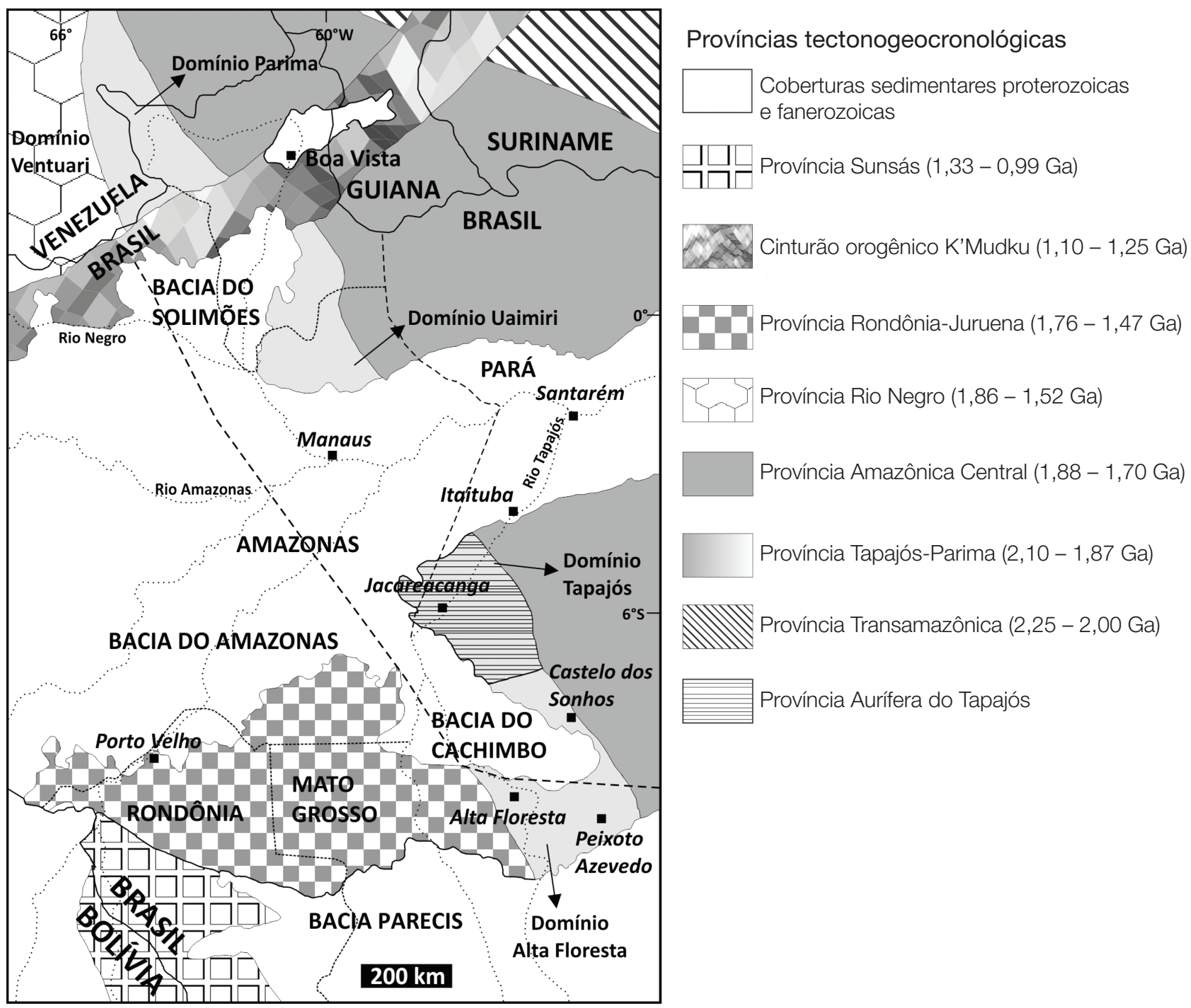

Figura 2. Mapa da porção centro-sul do Cráton Amazônico, que mostra os quatro domínios tectônicos da faixa orogênica Tapajós-Parima, bem como a localização da Província Aurífera do Tapajós (modificado de Santos et al., 2001). 
Apesar das divergências quanto à evolução geotectônica, há consenso na separação de dois domínios distintos (Santos et al., 2000; Santos et al., 2001; Vasquez et al., 2002): a oeste, o orogênico, constituído por sequências de retroarco e basaltos oceânicos, além de plútons cálcico-alcalinos de arcos magmáticos; e a leste, o anorogênico, de magmatismo alcalino intracontinental resultante do evento Uatumã.

Duas orogêneses, Mundurucus $(2040$ - $1957 \mathrm{Ma})$ e Tropas (1906 - $1886 \mathrm{Ma}$ ) (Figura 3), foram responsáveis pela formação da PAT $(\sim 2,10-1,87 \mathrm{Ga})$ (Santos et al., 2000), sendo que a primeira teve início com magmatismo de arco de ilha e sedimentação turbidítica em retroarco ou fossa oceânica. As mais antigas estruturas, produzidas por evento compressivo, são bem preservadas em rochas da porção centro-leste (Almeida et al., 2000) e definidas pela direção NE-SW da xistosidade de rochas do Grupo Jacareacanga e do bandamento dos gnaisses do Complexo Cuiú-Cuiú. Este grupo $(2,1-2,01 \mathrm{Ga})$ apresenta na base metabasaltos oceânicos e, no topo, metaturbiditos, intercalados com quartzitos, metassilexitos e formações ferríferas bandadas, enquanto aquele complexo é formado por rochas tonalíticas a granodioríticas, de natureza cálcico-alcalina, que representam o arco magmático mais antigo da região, datado em cerca de 2,0 Ga (Santos et al., 2000).

Seguiu-se, então, a formação dos arcos magmáticos Jamanxim (2000 - 1988 Ma) e Creporizão (1980 - $1957 \mathrm{Ma})$, os quais consistem de plútons cálcico-alcalinos de alto a médio K. Lamarão et al. (2002) e Lamarão, Dall'Agnol e Pimentel (2005) defendem a geração de outro arco magmático, representado por um conjunto de andesitos basálticos, traquiandesitos basálticos, traquitos, riolitos, tufos e brechas, metaluminosos a fracamente peraluminosos, de assinatura cálcico-alcalina de alto $\mathrm{K}$ a shoshonítica, os quais foram reunidos na Formação Vila Riozinho (2000 \pm 4 Ma e $1998 \pm 2$ Ma).

O segundo evento deformacional na PAT foi de caráter rúptil-dúctil em zonas de cisalhamento transcorrentes NWSE, de alto ângulo e cinemática sinistral, que foram responsáveis pela colocação de plútons cálcico-alcalinos de alto a médio K dos arcos magmáticos Creporizão e Tropas, este último após hiato de quase $50 \mathrm{Ma}$ e marcando o início da

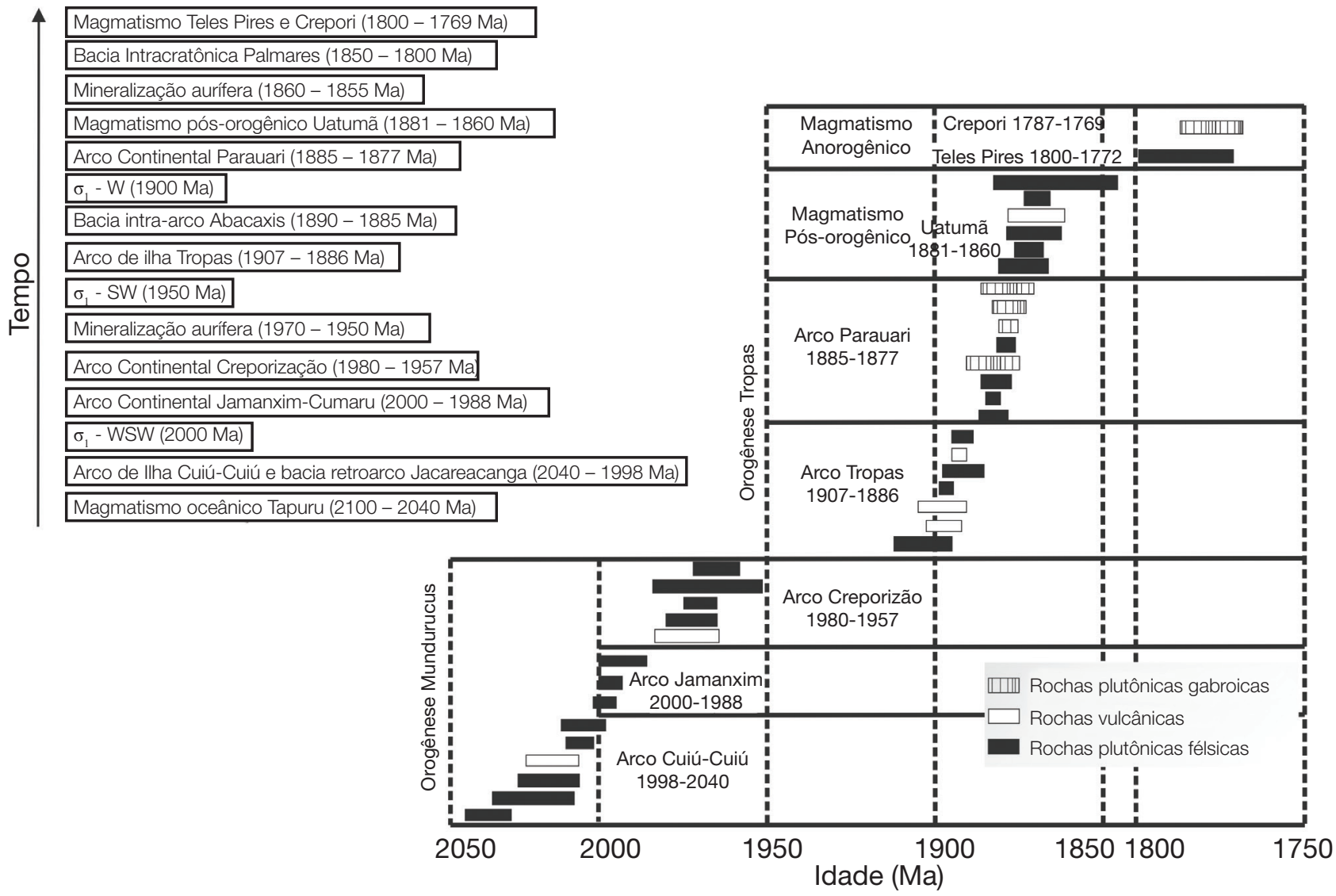

Figura 3. Síntese da evolução geológica do domínio Tapajós. À esquerda, a sequência de formação dos arcos magmáticos e bacias sedimentares, bem como dos eventos de deformação e da mineralização aurífera. À direita, o posicionamento temporal das orogêneses Mundurucus e Tropas com respectivos eventos magmáticos (baseado em Santos et al., 2004). A datação do evento mineralizador de 1,96 Ma é devida a Coutinho et al. (2000). $\sigma_{1}$ : direção da deformação. 
orogenia Tropas (Santos et al., 2001; Santos et al., 2004). Em bacias intra-arco foram depositados os sedimentos que deram origem às formações Abacaxis e Sequeiros, cujas fontes detríticas apresentam idade de 1,89 Ga.

A formação do arco magmático Parauari $(1,88 \mathrm{Ga})$ está relacionada à orogenia colisional oceano-continente (Santos et al., 2000, 2001), que foi seguida por episódio de tectônica extensional (E-W, NE-SW), decorrente da reativação de antigas zonas de fraqueza crustal ou da colocação da Suíte Intrusiva Maloquinha. As estruturas resultantes estão bem caracterizadas nas rochas gabroicas cálcico-alcali nas de alto K da Suíte Intrusiva Ingarana (1887 - $1878 \mathrm{Ma})$, nas rochas vulcânicas félsicas e piroclásticas alcalinas do Grupo Iriri, nos granitos alcalinos tipo A da Suíte Intrusiva Maloquinha e na Formação Bom Jardim (1881 Ma), composta por rochas vulcanoclásticas, lamprófiros, andesitos e dacitos. O Grupo Iriri e a Suíte Intrusiva Maloquinha representam manifestações magmáticas vinculadas ao evento vulcano-plutônico Uatumã (1,87 Ga).

A implantação de rifts continentais paleoproterozoicos no domínio Tapajós culminou com a deposição das coberturas sedimentares siliciclásticas da Formação Buiuçu e do Grupo Palmares. Os diques e soleiras do Diabásio Crepori cortam o embasamento orosiriano e mostram idade de $1780 \pm 7 \mathrm{Ma}$, a qual, além de datar esse evento magmático, indica a idade mínima de deposição das sequências sedimentares paleoproterozoicas. Os troctolitos da Suíte Intrusiva Cachoeira Seca (1186 $\pm 12 \mathrm{Ma})$ marcam reativação do manto sob o domínio Tapajós após hiato de $600 \mathrm{Ma}$. Santos et al. (2004) interpretaram o evento como um magmatismo alcalino esteniano relacionado a rifts continentais, reflexo da orogênese Sunsás.

Distintos depósitos auríferos têm sido reconhecidos na PAT com base em feições mesoscópicas, dados microtermométricos e de isótopos radiogênicos e estáveis, e enquadrados nos tipos lode, epitermais, porfiríticos e relacionados a intrusões graníticas (Jacobi, 1999; Santos et al. 2000; Juras, Gregersen, Alexander, 2011; Corrêa Silva, 2002; Juliani et al. 2002, 2005, 2008; Mello, 2007; Notto, 2007; Santiago, 2012).

Coutinho et al. (2000), baseados em assinaturas isotópicas de $\mathrm{Pb}$ em galena e pirita, sugerem duas fases mineralizantes. Por outro lado, Santos et al. (2001) consideram que houve apenas uma fase de mineralização, ocorrida há $1,86 \mathrm{Ga}$ ( $\mathrm{Pb}-\mathrm{Pb}$ em galena e $\mathrm{Ar}-\mathrm{Ar}$ em muscovita). No entanto, conforme Klein et al. (2002), dados estruturais de depósitos da porção sul da PAT são mais consistentes com dois estágios de mineralização distintos, o que é condizente com a proposta de Coutinho et al. (2000). O mais antigo, com idade entre 1,97 e $1,95 \mathrm{Ga}$, estaria relacionado à segunda fase de deformação na PAT, de direção NW-SE e se encaixaria no modelo dos depósitos orogênicos; e o outro, mais jovem $(1,88 \mathrm{Ga})$, aos eventos rúpteis $(\mathrm{E}-\mathrm{W})$ e teria propiciado a geração dos depósitos relacionados a intrusões.

\section{DEPÓSITO TOCANTINZINHO}

\section{Rochas hospedeiras e associadas}

O lineamento Tocantinzinho é uma estrutura regional de direção NW-SE ao longo da qual ocorrem vários corpos granitoides e depósitos de ouro, dentre eles o São Jorge, Palito, Batalha, Bom Jardim, Tocantinzinho e Cuiú-Cuiú. Essa estrutura controlou o alojamento das intrusões granitoides e a mineralização a elas relacionada.

$\mathrm{Na}$ área do depósito Tocantinzinho, ocorrem granitoides de composição sieno e monzogranítica, associados a aplitos e pegmatitos, provavelmente comagmáticos. Granodioritos e álcali-feldspato granitos também ocorrem, mas de forma subordinada. As rochas sieno/monzograníticas ocupam a zona central do depósito, sendo bordejadas em ambas as margens por quartzo monzonitos, como se neles fossem intrusivas, e são cortadas sucessivamente por diques andesíticos e riolíticos (Figuras 4A e 4B). Na realidade, as rochas andesíticas formam um corpo, hoje bastante erodido, o qual capeia boa parte das rochas sieno/monzograníticas e parece se afunilar e convergir em profundidade para possíveis diques alimentadores do magma que o gerou. $\mathrm{O}$ dique de riolito é porfirítico e claramente corta as rochas andesíticas. Não expostas em superfície, rochas quartzo latíticas, também porfiríticas, foram interceptadas localmente por furo de sondagem (Mello, 2007). Essas variadas rochas vulcânicas indicam que um sistema magmático esteve ativo em profundidade mesmo após os granitoides hospedeiros terem sido suficientemente resfriados, o que deve ter favorecido elevados gradientes termais e, em decorrência, a textura porfirítica nelas observada.

Os granitoides constituem um corpo essencialmente isótropo, alongado na direção NW-SE (granito Tocantinzinho). Ainda não datados, os diques de andesito e riolito têm sido correlacionados à Formação Vila Riozinho (Mello, 2007), cuja idade foi determinada em $2000 \pm 4$ / $1998 \pm 2$ Ma (Lamarão, Dall'Agnol, Pimentel, 2005). A escassez de afloramentos e a limitada área para observações de campo não permitem, por ora, estabelecer relações de contato da intrusão granítica com unidades litoestratigráficas mais antigas da Província Aurífera do Tapajós. Com base no geobarômetro da hornblenda, foram estimadas pressões de 1,9 a 2,8 kbar (Santiago, 2012), o que corresponde a profundidades de alojamento daqueles granitoides entre 7 e $10 \mathrm{~km}$, aproximadamente. A presença na área do depósito de rochas graníticas com características subvulcânicas pode, entretanto, indicar que este intervalo foi superestimado.

A fácies sieno/monzogranítica, de coloração rósea clara e granulação média a grossa (Figura $5 \mathrm{~A}$ ), é composta por microclina $(40-50 \%)$, oligoclásio $(20-35 \%)$, quartzo $(20-30 \%)$, biotita annítica $(2-8 \%)$ e Fe-edenita $(0-2 \%)$, em geral dispostos em arranjo granular hipidiomórfico a 

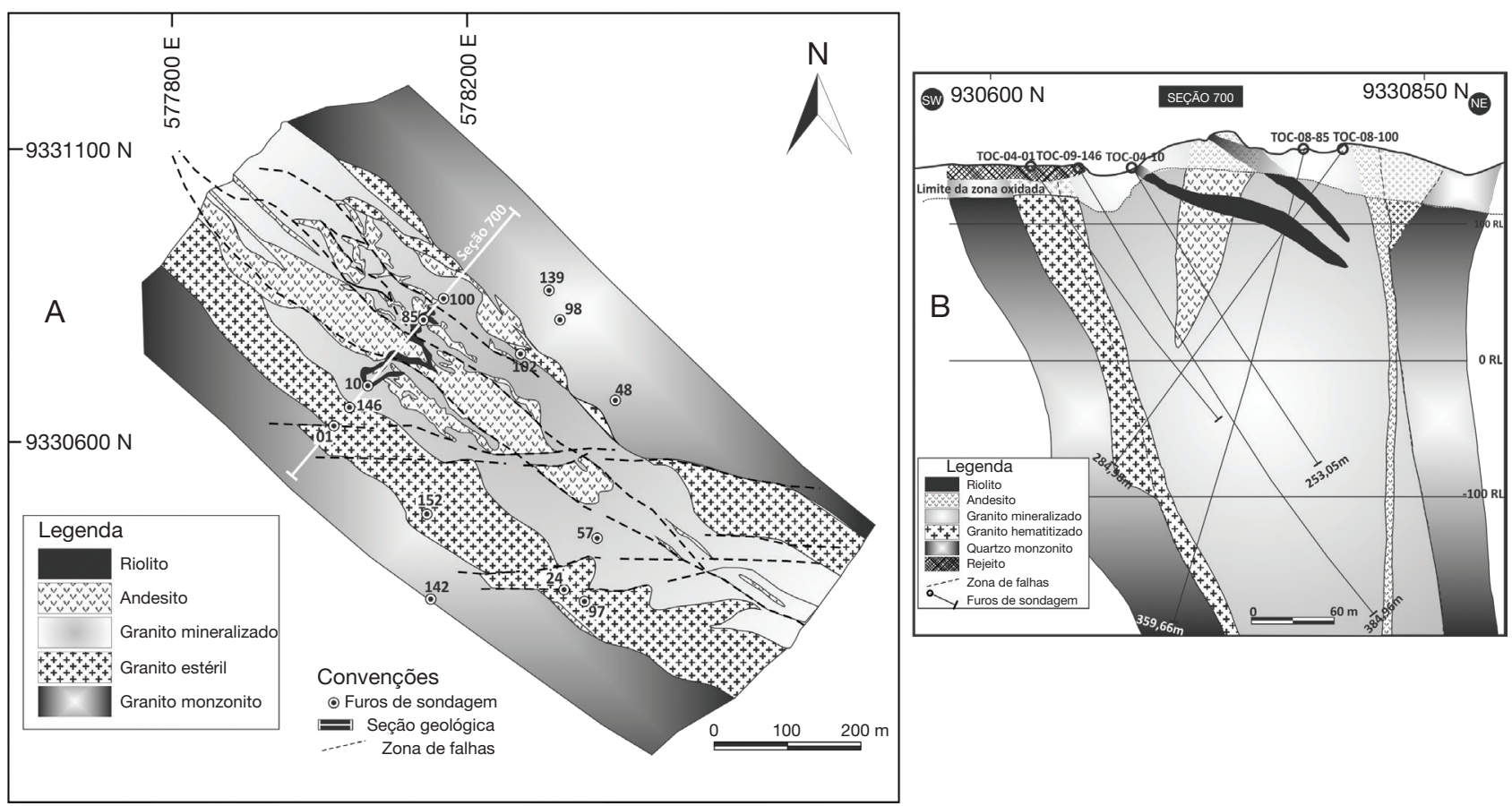

Figura 4. Mapa geológico (A) e seção geológica (700) SW-NE (B) do depósito Tocantinzinho (modificado de Juras, Gregersen, Alexander, 2011).

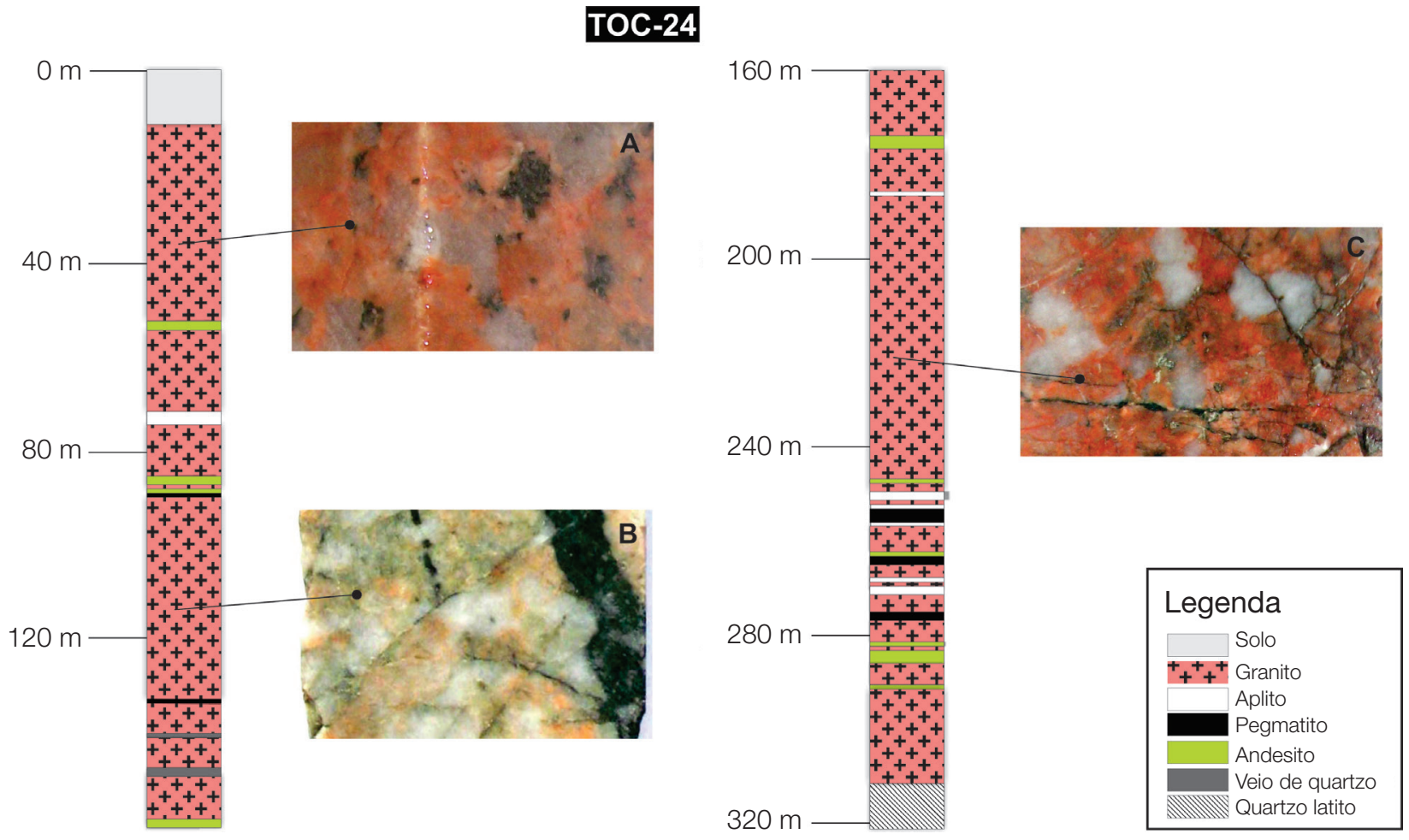

Figura 5. Perfil do furo de sondagem TOC-24, representativo do depósito Tocantinzinho, mostrando as variedades de rochas graníticas pouco alteradas $(A)$, a variedade salame com finas vênulas de clorita e quartzo leitoso (B) e a variedade smoky com veio centimétrico de clorita (C). 
alotriomórfico com desenvolvimento local de texturas poiquilítica e rapakivi. Os principais minerais acessórios primários são zircão, magnetita, apatita, allanita, monazita, U-thorita e titanita, sendo clorita e fengita importantes fases secundárias (Santiago, 2012). As rochas granodioríticas mostram coloração cinza esbranquiçada e granulação média, ao passo que as variedades de álcali-feldspato granito são grossas e de coloração fortemente avermelhada. Por seu turno, a fácies quartzo monzonítica se diferencia da fácies sieno/monzogranítica pela coloração cinza avermelhada, granulação fina a média e menores proporções de quartzo. Normalmente são magnéticas e adquirem coloração verde avermelhada quando intensamente epidotizadas.

As rochas do granito Tocantinzinho mostram caráter essencialmente metaluminoso e foram cristalizadas de magma sob condições intermediárias de fugacidade de oxigênio, o que as enquadram no tipo oxidado da série da ilmenita (Santiago, 2012). Esse corpo granítico não apresenta evidências de deformação dúctil, porém se encontra bastante fraturado e localmente brechado. Esse quebramento resultou provavelmente de faturamento hidráulico provocado pela exsolução de soluções aquosas dissolvidas no magma granítico, as quais teriam migrado pelos espaços que então foram abertos e neles precipitaram quartzo + clorita. As vênulas resultantes mostram-se, contudo, estéreis. Segundo Mello (2007), esse selamento preparou o granito para a nova fase de faturamento que ele teria experimentado durante a atividade magmática subsequente e responsável pelas vênulas mineralizadas. Estas vênulas são em geral milimétricas e ocorrem em folhas (sheeted veinlets) com direção preferencial ENE-WSW e mergulhos subverticais.

\section{Idade do granito Tocantinzinho}

Cristais de zircão foram extraídos de duas amostras do granito Tocantinzinho (TOC-102-05 e TOC-103-05) e alguns deles selecionados para análises por evaporação de $\mathrm{Pb}$, constando os resultados na Tabela 1. Valores das razões ${ }^{206} \mathrm{~Pb} /{ }^{204} \mathrm{~Pb}$ inferiores a 2500 foram desprezados para minimizar os efeitos da correção de $\mathrm{Pb}$, os quais afetam comumente as razões dos isótopos radiogênicos — daí não aparecerem na tabela.

No geral, as duas amostras exibem cristais de zircão incolores a acastanhados, hábitos prismáticos bipiramidais, raramente arredondados, e zoneamento magmático, além de microfraturas e inclusões minerais (Figura 6).

Foram analisados 15 grãos da amostra TOC-103-05, porém três deles foram excluídos (TOC-103-05/3, TOC$103-05 / 5$ e TOC-103-05/21) por apresentarem inadequadas razões ${ }^{206} \mathrm{~Pb} /{ }^{204} \mathrm{~Pb}$, enquanto outros dois (TOC-10305/26 e TOC-103-05/27) não foram aproveitados por terem revelado idade muito jovem, salvo na etapa a $1.450^{\circ} \mathrm{C}$ para o grão TOC-103-05/26, bem como altos erros (Tabela 1). Apenas um grão (TOC-103-05/13) revelou idade arqueana $(2867 \pm 6 \mathrm{Ma})$, o que muito provavelmente indica componente de $\mathrm{Pb}$ herdado. Os cálculos para os nove grãos restantes acusaram idades que variam de $1983 \mathrm{Ma}$ a $2112 \mathrm{Ma}$, com média de $2070 \pm 34$ Ma e Mean Square Weighted Deviation (MSWD) igual a 142. Os elevados valores do erro e do MSWD, certamente condicionados pela diferença de quase 130 Ma daquele intervalo, fazem a idade determinada ser de baixa precisão. Distinguem-se, no entanto, duas populações de zircão (Tabela 1), uma com idade média de $1999 \pm 16 \mathrm{Ma}(\mathrm{MSWD}=4)$ e a outra com idade relativamente mais antiga, de $2094 \pm 9(\mathrm{MSWD}=4)$.

Da amostra (TOC-102-05), foram analisados 45 grãos, tendo apenas 24 fornecido resultados isotópicos satisfatórios (Tabela 1). A etapa a $1.450^{\circ} \mathrm{C}$ referente ao grão TOC102-05/04 foi descartada por ter apresentado idade relativamente mais jovem (1922 Ma). Optou-se, também, por excluir o grão TOC-102-05/31, o qual mostrou a idade mais antiga e erro muito alto, o que poderia elevar o valor do MSWD. Outros três grãos foram eliminados por revelarem idades relativamente mais antigas (2029 a $2068 \mathrm{Ma})$ com erros elevados, que provavelmente indicariam componente de $\mathrm{Pb}$ herdado. Os resultados obtidos para os grãos remanescentes apresentaram idade de $1979 \pm 7 \mathrm{Ma}$ com MSWD igual a 10, o qual the empresta pouca confiabilidade e poderia ter sido influenciado pelos grãos TOC102-05/11, TOC-102-05/13, TOC-102-05/25, TOC-10205/32, TOC-102-05/37 e TOC-102-05/42. Novo cálculo foi, então, realizado sem estes grãos, registrando-se idade média de $1975 \pm 7$ Ma e MSWD = 7,5. Em seguida, foram desconsiderados sete outros grãos, que mostraram erros mais elevados e/ou idades relativamente mais jovens, determinando-se, então, valor médio de $1982 \pm 8$ Ma com MSWD igual a 5 (Figura 7), o qual corresponderia à mais provável idade de cristalização do granito Tocantinzinho.

\section{Alteração hidrotermal}

Fluidos hidrotermais alteraram e mineralizaram o granito Tocantinzinho, produzindo, além do depósito de ouro, rochas hematitizadas e duas variedades informalmente designadas de salame e smoky (Figuras 5B e 5C) pelos técnicos das empresas que têm operado na área. Muito embora essas rochas não mostrem foliação penetrativa, observa-se fraca orientação de cristais de quartzo.

As rochas graníticas hematitizadas são estéreis e apresentam coloração rósea a avermelhada devido à densa rede de microfraturas preenchidas com hematita que as cortam e à abundância de feldspato potássico micropertítico, sendo que o último confere a eles composição de álcali-feldspato granito a sienogranito. A distribuição espacial é tal que, nas zonas mais internas do depósito, essas rochas balizam, 
Tabela 1. Dados isotópicos de evaporação de Pb em monocristais de zircão para as amostras TOC-102-05 e TOC-10305 do Granito Tocantinzinho.

\begin{tabular}{|c|c|c|c|c|c|c|c|c|c|c|c|c|c|}
\hline 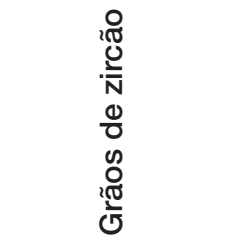 & $\begin{array}{l}0 \\
\circ \\
\vdash\end{array}$ & 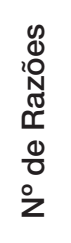 & 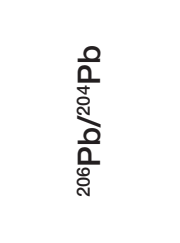 & 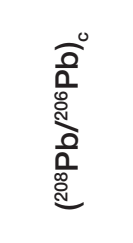 & $\stackrel{\mathfrak{Q}}{N}$ & $\begin{array}{l}\frac{0}{0} \\
\frac{0}{0} \\
\frac{0}{2} \\
\frac{0}{0} \\
\frac{2}{2}\end{array}$ & $\stackrel{b}{N}$ & 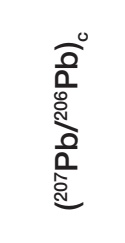 & $\stackrel{\bullet}{N}$ & $\begin{array}{l}\frac{0}{0} \\
\frac{0}{\pi} \\
\frac{\pi}{0} \\
\frac{\pi}{0} \\
\frac{0}{0} \\
\frac{\pi}{0} \\
\frac{\pi}{0}\end{array}$ & $\stackrel{b}{N}$ & 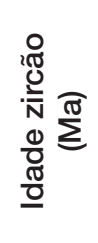 & \\
\hline C-102-05/2 & 1.450 & 8 & $7.194,2$ & 0,29994 & 0,00186 & 0,12337 & 0,00046 & 0,12152 & 0,00 & 1979 & 8 & & 8 \\
\hline \multirow{2}{*}{ TOC-102-05/4 } & $1.450^{\star}$ & 4 & 3.937 & 0,25662 & 0,00213 & 0,12115 & 0,00030 & 0,11774 & 0,00030 & 1922 & 5 & & \\
\hline & $1.450^{*}$ & 8 & 1.000 .000 & 0,26996 & 0,00674 & 0,12187 & 0,00146 & 0,12187 & 0,00146 & 1984 & 21 & 1984 & $L_{1}$ \\
\hline TOC-102-05/9 & $1.450^{\star}$ & 8 & 3.921 & 0,23994 & & 0,12316 & & & & 1953 & 11 & 1953 & 11 \\
\hline TOC-102-05/11 & $1.500^{\star}$ & 8 & 7.246 & ,29451 & & 0,12314 & & 0,12130 & & 1976 & 30 & & \\
\hline TOC-102-05/13 & $1.450^{*}$ & 16 & 3.215 & 28576 & & 0,12539 & & 92 & & 1970 & 32 & 70 & \\
\hline TOC-102-05/14 & $1.450^{\star}$ & 4 & 10.417 & 31174 & & 0,12624 & & & & 2029 & 17 & 029 & 17 \\
\hline$-102-05 / 15$ & $1.450^{\star}$ & 8 & 1.000 .000 & 30200 & & 0,12780 & & 80 & & 2068 & 9 & 2068 & 9 \\
\hline \multirow{2}{*}{ TOC-102-05/17 } & 1.450 & 4 & 7.874 & 0,29651 & 0,00193 & 0,12441 & & 0,12272 & & 1996 & 12 & 1996 & 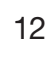 \\
\hline & $1.500^{*}$ & 8 & 1.000 .0 & 32111 & & 0,12499 & & & & 2029 & 36 & & \\
\hline \multirow{2}{*}{ TOC-102-05/18 } & 1.450 & 6 & & 0,25761 & & 0,12483 & & & & 1996 & 14 & 1996 & \\
\hline & $1.500^{\star}$ & 24 & 10.309 & 0,29733 & 0,00 & 0,12466 & 0,00 & 0,12508 & 0,00250 & 2030 & 35 & & \\
\hline \multirow{2}{*}{ TOC-102-05/19 } & 1.450 & 26 & 3.390 & 0,21378 & 0,0 & 0,12549 & 0,0 & 0,12182 & & 1983 & 8 & 1983 & 8 \\
\hline & $1.500^{*}$ & 34 & $>1.000 .00$ & 0,27249 & 0,00956 & 81 & 0,00 & & 0,0 & 2055 & 30 & & \\
\hline \multirow{2}{*}{ TOC-102-05/20 } & $1.450^{\star}$ & 8 & 50 & 0,27530 & 0,0 & 0,12223 & & 0,1 & & 1958 & 79 & & \\
\hline & $1.500^{\star}$ & 32 & & 452 & & 09 & & & & 0 & 24 & 2000 & 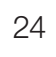 \\
\hline $2-05 / 23$ & $1.450^{\star}$ & 8 & 5.155 & 0,26609 & 0, & 0,12910 & & 53 & & 2051 & 65 & 2051 & 65 \\
\hline \multirow{2}{*}{ TOC-102-05/25 } & $1.450^{*}$ & 16 & 4.167 & 0,31190 & & 31 & & & & 1969 & 37 & 1969 & 37 \\
\hline & $1.500^{\star}$ & 16 & $>1.000 .0$ & 0,38992 & & & & & & 2029 & 33 & & \\
\hline 26 & 1.450 & 38 & & 0,26387 & & 356 & & & & 2 & 9 & & \\
\hline$-102-05 / 28$ & 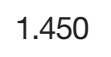 & 8 & & 3 & & 70 & & & & 30 & $\checkmark$ & 30 & \\
\hline $2-05 / 30$ & $0^{*}$ & 4 & 9 & 6596 & & 49 & & & & 66 & 4 & 966 & 4 \\
\hline & $1.450^{\star}$ & 6 & 1.000 .000 & 0,35984 & & 745 & & & & 2196 & 67 & 2196 & 67 \\
\hline \multirow{2}{*}{ TOC-102-05/32 } & $1.450^{\star}$ & 8 & 18.518 & 0,20752 & 0,0 & 0,12427 & & & & 2009 & 10 & 2009 & 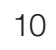 \\
\hline & & 8 & & 3886 & & & & & & 1973 & 47 & & \\
\hline \multirow{2}{*}{ TOC-102-05/37 } & $1.450^{*}$ & 8 & & 3437 & & 88 & & & 0,0 & 2010 & 21 & 2010 & 21 \\
\hline & $1.500^{*}$ & 8 & 10 & 5776 & 0,0 & 25 & & & & 1945 & 189 & & \\
\hline & $1.450^{\star}$ & 22 & & 0,21397 & 0,0 & 427 & 0,0 & & & 1972 & 26 & 1972 & 26 \\
\hline $02-05 / 42$ & $1.500^{*}$ & 16 & & 25821 & & & & & & 2007 & 9 & & 9 \\
\hline 4 & & 8 & & & & & & & & 6 & 18 & 1966 & 18 \\
\hline TCO-102-05/45 & $1.450^{*}$ & 8 & 5.076 & 0,28038 & & 42 & & & 0,00087 & 1968 & 13 & 1968 & 13 \\
\hline \multicolumn{8}{|c|}{$Z r 2+Z r 17+Z r 18+Z r 19+Z r 26+Z r 28$ (MSWD = 5) } & \multicolumn{6}{|c|}{ Idade média $=1982 \pm 8 \mathrm{Ma}$} \\
\hline TO & & 32 & 12.048 & 7584 & & & & & & 1992 & 8 & 1992 & 3 \\
\hline $03-05 / 4$ & $1.450^{*}$ & 6 & 1.0 & 12 & & & & & & 2028 & 17 & & \\
\hline$-103-05 / 8$ & 1.500 & 22 & & 0,18629 & 0,0028 & 0,13505 & 0,00063 & 0,13088 & 0,00096 & 2110 & 13 & 10 & 13 \\
\hline$-103-05 / 10$ & 1.450 & 6 & & 16049 & 0056 & 0,12987 & 0,00315 & 0,1287 & 0,00317 & 2081 & 43 & 2081 & 43 \\
\hline 03-05/11 & 1.450 & 8 & & 0,17153 & 0,01172 & 0,1325 & 0,00123 & & 0,00123 & 2112 & 17 & 2112 & 17 \\
\hline \multirow{2}{*}{ TOC-103-05/12 } & $1.450^{\star}$ & 34 & 4.504 & 0,13961 & 0,00111 & 0,13275 & 0,00039 & 0,12957 & 0,00037 & 2092 & 5 & & \\
\hline & & 26 & & & & 0,13163 & 0,00 & 0,12963 & 0,0003 & 2093 & 4 & 2093 & 3 \\
\hline 13 & $1.500^{*}$ & 36 & 3.831 & 0,09025 & 0,00127 & 0,20798 & 0,00048 & 0,20506 & 0,00072 & 2867 & 6 & & \\
\hline \multirow{2}{*}{ TOC-103-05/23 } & $1.450^{*}$ & 8 & 3.922 & 0,23477 & 0,00158 & 0,12457 & 0,00088 & 0,12116 & 0,00099 & 1974 & 15 & & \\
\hline & 1.500 & 32 & 8.130 & 0,35567 & 0,00201 & 0,12396 & 0,00055 & 0,12183 & 0,00148 & 1983 & 22 & 1983 & 22 \\
\hline
\end{tabular}


Tabela 1. Continuação.

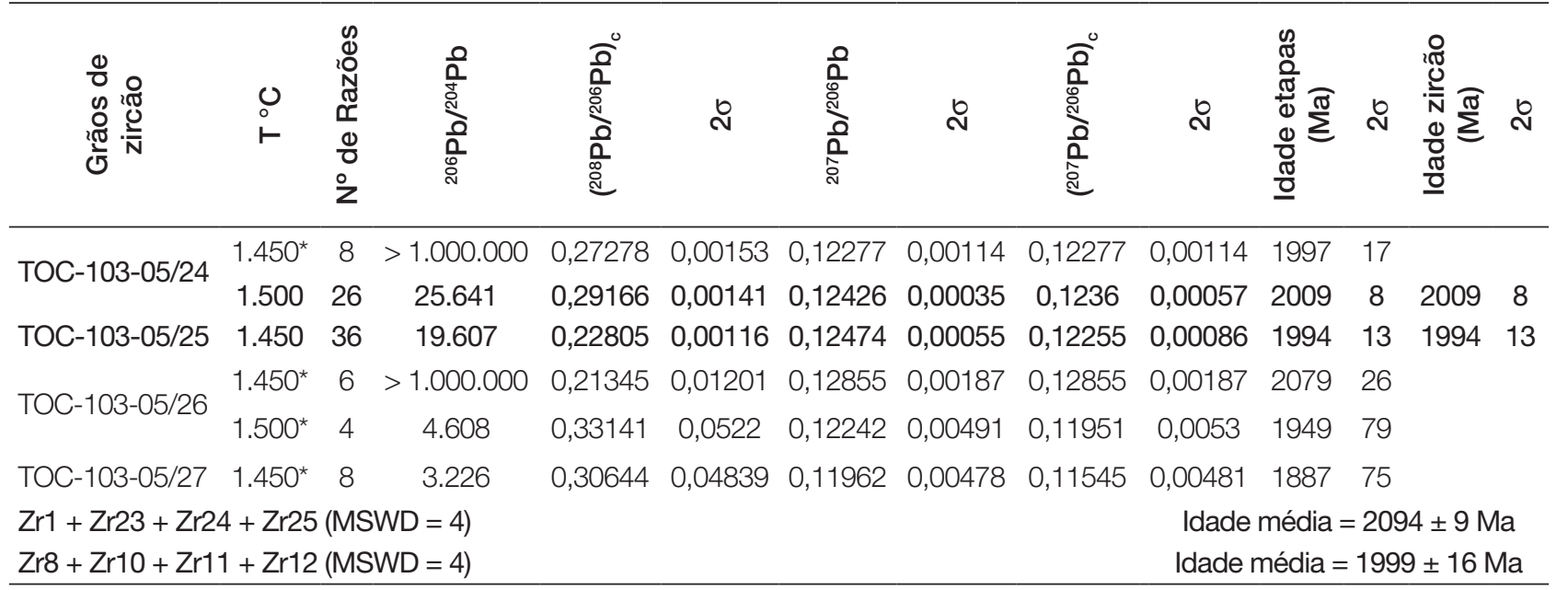

*Excluídos do cálculo da idade; Valores em negrito: usados para o cálculo das idades; MSWD: Mean Square Weighted Deviation; c: razão corrigida conforme Stacey e Kramers (1975); 2๘: erro analítico.
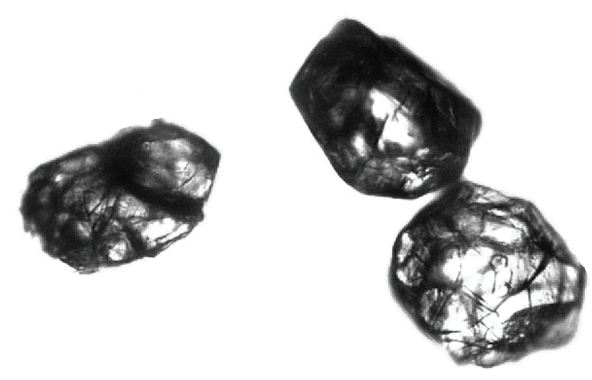

TOC-102-05/2

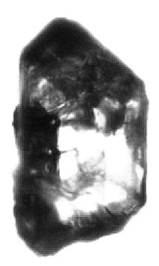

TOC-102-05/19

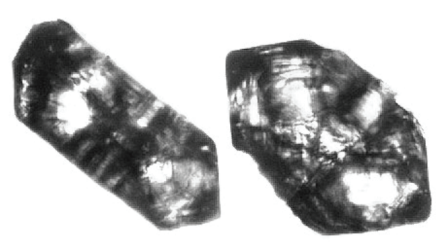

TOC-102-05/17

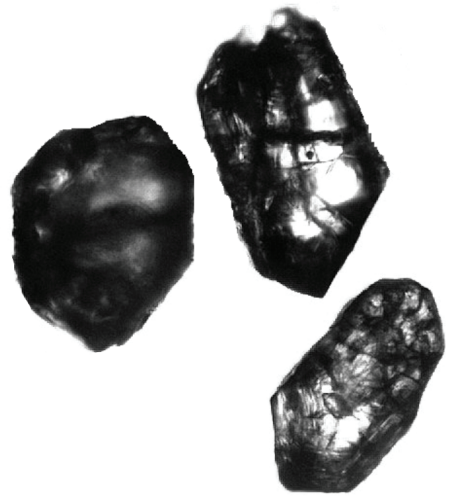

TOC-102-05/26

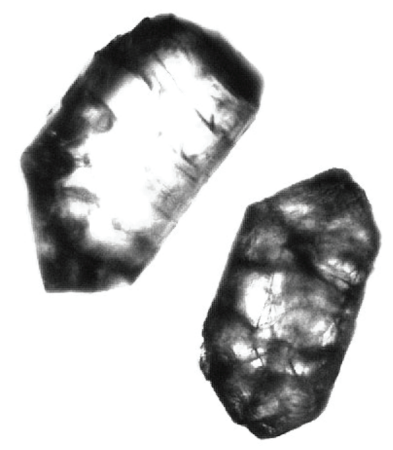

TOC-102-05/18

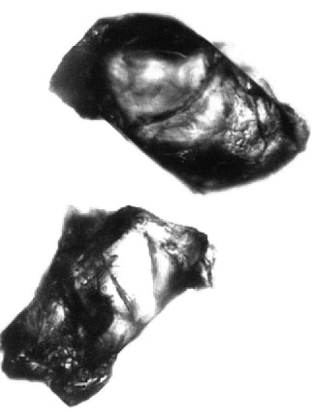

TOC-102-05/28

$0,1 \mathrm{~mm}$

Figura 6. Feições morfoscópicas dos cristais de zircão que foram usados na datação do granito Tocantinzinho. 
ainda que com contatos mal definidos, as variedades salame e smoky, ambas mineralizadas, enquanto mais externamente guardam contatos com o quartzo monzonito, alguns deles de caráter tectônico (Figura 4).

A variedade salame mostra cristais grossos de microclina muito avermelhados a róseos, bem como de quartzo de coloração esbranquiçada a quase leitosa, cujo aspecto justifica a denominação que the foi dada. Os cristais de quartzo apresentam, em geral, forma ameboidal, que parece ter resultado de sobrecrescimento proporcionado por fluidos ricos em sílica. Também rica em microclina e nesse tipo textural de quartzo, a variedade smoky diferencia-se pela coloração esverdeada com tons acinzentados a esbranquiçados. É possível constatar, em um mesmo furo, intervalos métricos dominados ora por uma ora por outra variedade, ou outros em que elas estão difusamente mescladas, parecendo haver completa gradação. Embora distintas macroscopicamente, as variedades não apresentam diferenças mineralógicas marcantes, mesmo quando mais intensamente alteradas. Do ponto de vista químico, há muita similaridade, ainda que a variedade smoky apresente menores teores de $\mathrm{Na}_{2} \mathrm{O}$, em geral abaixo de $3,2 \%$, e teores médios de $\mathrm{MgO}$ em torno de $1 \%$, quase o dobro do da variedade salame (Santiago, 2012). Constata-se também que as maiores razões $\mathrm{Fe}_{2} \mathrm{O}_{3} / \mathrm{FeO}$ pertencem à variedade smoky, o que torna difícil sustentar a hipótese corrente de que a coloração avermelhada da variedade salame é devida à impregnação com óxido férrico.

Considerando-se a evolução do paleossistema hidrotermal Tocantinzinho, pôde-se reconhecer um estágio mais precoce (E1), que redundou na formação de vênulas de quartzo + clorita não mineralizadas. No estágio seguinte (E2), não necessariamente ligado ao resfriamento/cristalização do

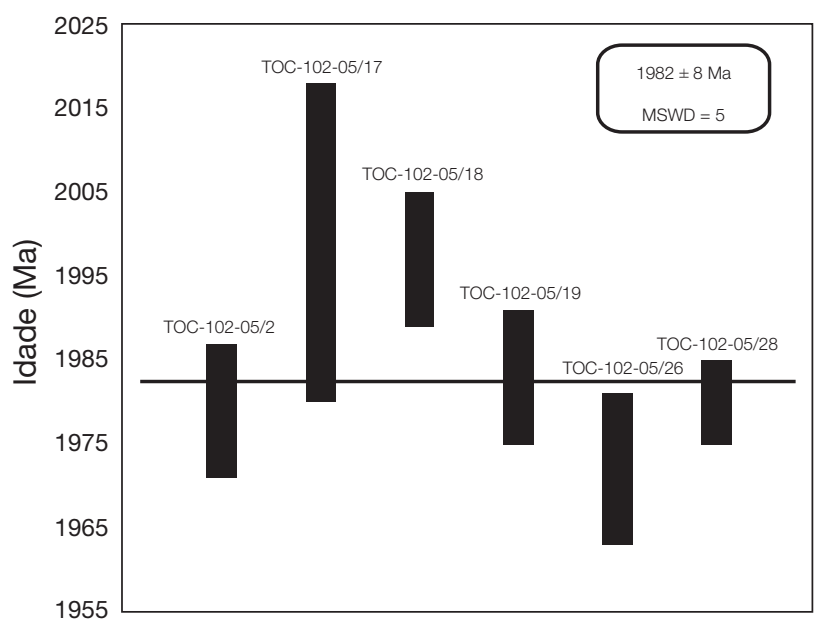

Grãos de Zircão

Figura 7. Diagramas de evaporação de $\mathrm{Pb}$ para cristais de zircão da amostra TOC-102-05 do granito Tocantinzinho. As barras correspondem ao intervalo de erro para a idade média de cada grão de zircão. MSWD: Mean Square Weighted Deviation. granito Tocantinzinho, mas durante o qual ocorreu a mineralização, foram identificados cinco tipos principais de alteração, que se sucederam na seguinte ordem: microclinização, cloritização, sericitização, silicificação e carbonatação. Convém ressaltar que, à exceção do carbonato, houve precipitação de clorita, sericita e quartzo ao longo de todo o estágio E2 e que a referência àqueles tipos significa bem mais a dominância de um destes minerais nas amostras estudadas.

Durante a microclinização, foi gerada a variedade salame a partir da substituição isoquímica do feldspato potássico primário por microclina hidrotermal, ao mesmo tempo em que o quartzo experimentava sobrecrescimento e adquiria aspecto leitoso.

A clorita, de composição dominantemente chamosítica, deriva da substituição de fases máficas, sobretudo biotita, e é também constituinte de vênulas mono ou poliminerálicas (quartzo \pm rutilo \pm carbonato \pm fengita \pm calcopirita \pm pirita). Em algumas amostras menos alteradas, identificou-se clinocloro, cuja formação pode ter sido favorecida por microambientes mais enriquecidos em $\mathrm{Mg}$ (maior interação dos fluidos hidrotermais com as rochas andesíticas) ou zonas que registraram temperaturas menos elevadas.

A sericitização é marcada pela ubíqua produção de fengita, um dos mais abundantes produtos hidrotermais do paleossistema Tocantinzinho, que ocorre em finas lamelas em substituição ao plagioclásio e à biotita. Por ter sido contemporânea com a mineralização, a sericitização muito provavelmente resultou da ação dos mesmos fluidos que precipitaram os sulfetos e o ouro. A associação fengita + quartzo + pirita \pm calcopirita \pm esfalerita \pm galena \pm ouro é comum em vênulas ou ocorre disseminada, especialmente onde o plagioclásio foi intensamente destruído. Abundante fengita também foi formada nas zonas brechadas e densamente fraturadas que exibem cristais de plagioclásio com maclas deformadas e cortadas por rede de vênulas compostas exclusivamente por fengita. O ouro está intimamente associado à pirita nas zonas sericitizadas.

A silicificação e a carbonatação foram os estágios subsequentes e marcados, respectivamente, pela precipitação de quartzo e calcita, principalmente em planos de fratura e zonas bechadas.

A avaliação do balanço de massa decorrente desses processos hidrotermais mostrou que houve maiores ganhos de massa por unidade de volume na variedade smoky do que na variedade salame (Santiago, 2012), o que pode configurar importante diferença geoquímica entre elas.

\section{Mineralização}

O corpo mineralizado ocupa volume de pouco mais de $0,03 \mathrm{~km}^{3}$ e é constituído, além do ouro, por pirita, calcopirita, galena e esfalerita (Figuras 8A a 8C), bem como pela ganga, em que figuram outros produtos hidrotermais e constituintes 
do próprio granito hospedeiro. Os sulfetos, que raramente ultrapassam $3 \%$ do volume das rochas, ocorrem principalmente em vênulas ricas em quartzo, as quais se mostram finamente espaçadas e separadas por rocha estéril (sheeted quartz veinlets), configurando-se localmente o estilo stockwork. Além do quartzo, são minerais comuns a clorita e a fengita. Essas vênulas, de espessura micrométrica a centimétrica, estão normalmente encaixadas em granito de granulação grossa e mostram direções preferenciais $\mathrm{N} 20-30^{\circ} \mathrm{E}$ e $\mathrm{N} 70-80^{\circ} \mathrm{E}$. Do ponto de vista paragenético, são distinguidos, na zona mineralizada, dois sistemas de vênulas: um precoce, constituído por quartzo, clorita, pirita e ouro, e outro tardio, composto por quartzo, pirita, clorita, calcita, ouro, \pm calcopirita \pm galena \pm esfalerita (Mello, 2007).
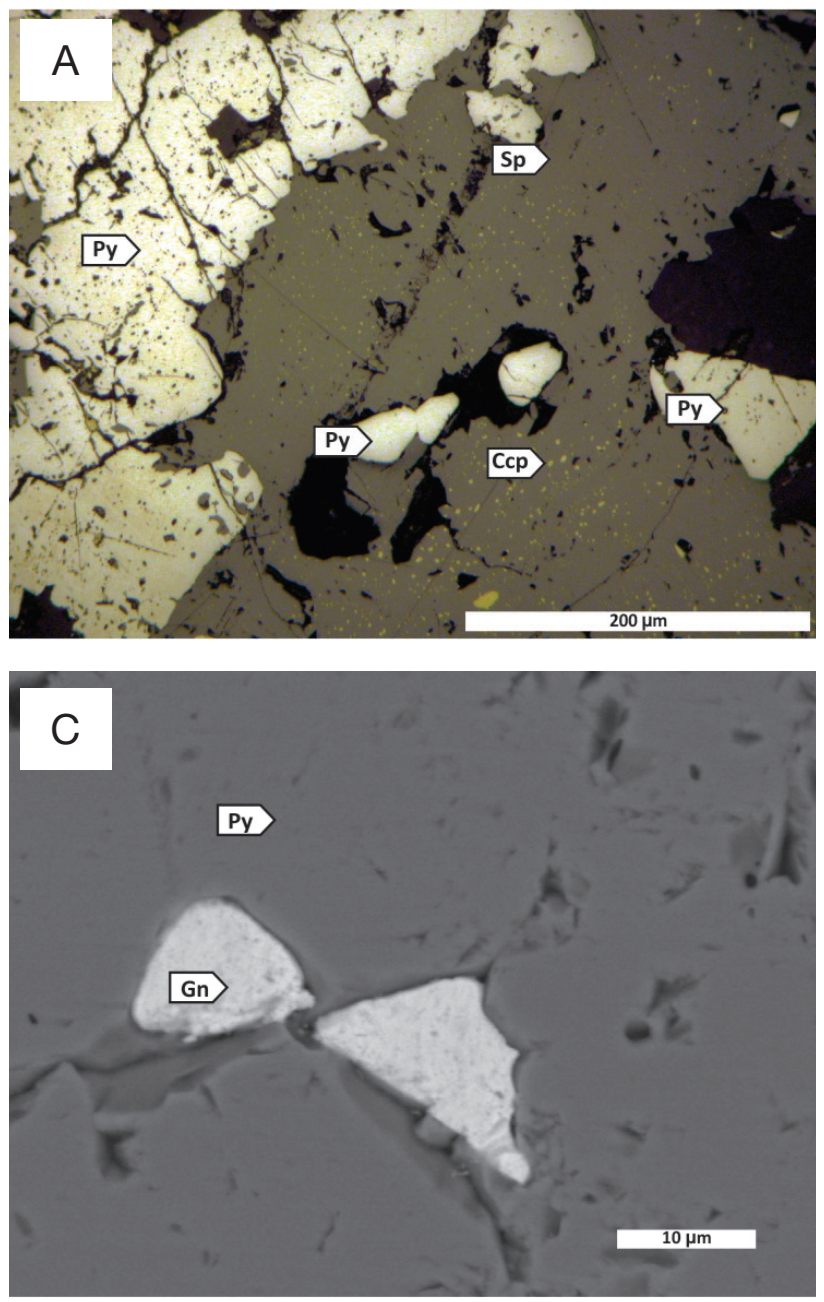

Nas zonas ricas em vênulas de quartzo-clorita, sem sulfetos de metais-base, também se observam disseminações de pirita na rocha, porém o ouro só revela valores econômicos pontualmente. Onde as vênulas com sulfetos de metais-base são abundantes, o ouro apresenta teores mais elevados e chega a ser visível a olho nu, o que só se constata quando os sulfetos exibem granulação grossa. Apesar da relação direta entre as concentrações de ouro e a quantidade de sulfetos de metais-base, não é neles que o ouro está principalmente contido e sim na pirita (Figura 8D), na qual ocorre em partículas muito finas, conforme mencionado adiante.

Porções brechadas são comuns em testemunhos de alguns furos de sondagem, constituindo corpos de pequenas dimensões desprovidos de ouro e sulfetos. As características
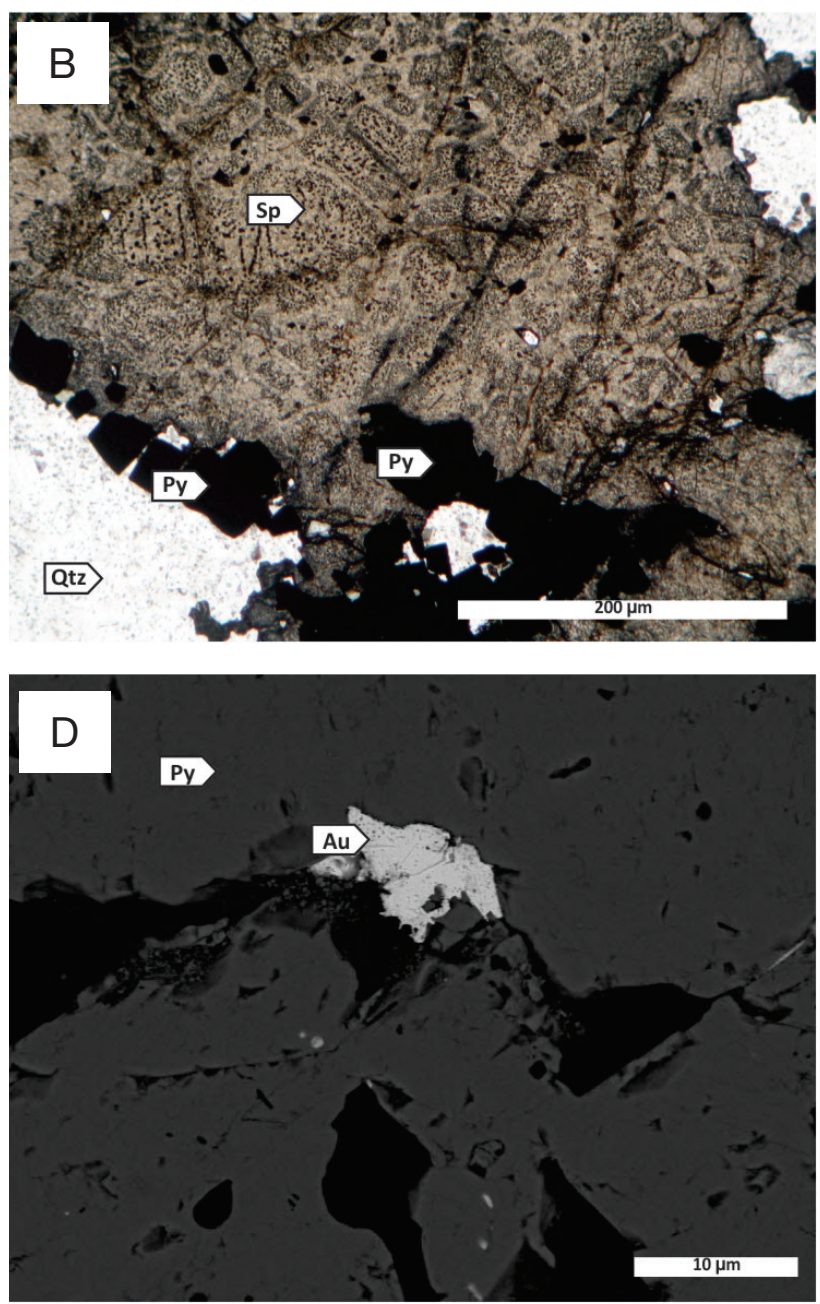

Figura 8. Minerais de minério do depósito Tocantinzinho: fotomicrografias (A e B) e imagens de elétrons retoespalhados obtidas por microscopia eletrônica de varredura (C e D). (A) Esfalerita em aparente substituição à pirita. Notar também as finas inclusões de pirita e as finíssimas lamelas de calcopirita exsolvidas da esfalerita (nicois paralelos e luz refletida); (B) Cristais de esfalerita de coloração amarronzada e hábito coloforme associados à pirita e ao quartzo (nicois paralelos e luz transmitida); (C) Inclusões anedrais de galena em pirita; (D) Lamelas de ouro no interior de cristal de pirita. As áreas mais escuras correspondem a vazios. Au: ouro; Esf: esfalerita; Gl: galena; Py: pirita; Cpy: calcopirita; Qtz: quartzo. 
destes corpos são indicativas de que não resultaram de tectonismo e sim de processos magmático-hidrotermais.

Tentou-se datar a mineralização usando-se o método $\mathrm{Pb}-\mathrm{Pb}$ (evaporação) em quatro partículas de $\mathrm{Au}$, de tamanho milimétrico, associadas a sulfetos e presentes na variedade smoky. As razões ${ }^{206} \mathrm{~Pb} / 204 \mathrm{~Pb}$ e ${ }^{207} \mathrm{~Pb} / 204 \mathrm{~Pb}$ se mostraram homogêneas, variando de 16,51 a 17,91 e de 15,49 a 15,63, respectivamente. Em diagrama ${ }^{207} \mathrm{~Pb} /{ }^{204} \mathrm{~Pb} \times{ }^{206} \mathrm{~Pb} / 204 \mathrm{~Pb}$, forneceram idade de $1443 \pm 460 \mathrm{Ma}$ com $\mathrm{MSWD}=0,49$. O elevado erro desautoriza, infelizmente, qualquer interpretação que possa ter significado geológico. Neste mesmo diagrama, de acordo com o modelo de Doe e Zartman (1979), as composições das partículas se situam entre as curvas evolutivas propostas para o manto e orógenos, que poderiam ser os prováveis reservatórios dos quais o Au foi extraído.

\section{Associação metálica}

Amostras das variedades salame e smoky foram dosadas para metais e semimetais selecionados, conforme resultados apresentados na Tabela 2. Cádmio, selênio e antimônio revelaram, em quase todas as amostras, teores abaixo do limite de detecção da técnica utilizada. Da mesma forma aconteceu com o mercúrio em cerca de $60 \%$ delas, não ultrapassando 0,08 ppm nas demais. Por esta razão, não foram incluídos na Tabela 2. Chamam a atenção os baixos conteúdos de Sn (1 e 5 ppm) e os de Nb, que são bastante superiores aos de $\mathrm{Ta}$, proporcionando razões $\mathrm{Nb} / \mathrm{Ta}$ entre 9,5 e 30. O Mo apresenta concentrações abaixo de 4 ppm, exceto em uma amostra (TOC-97A-05), na qual atinge $23,8 \mathrm{ppm}$, exatamente a que revela praticamente o mesmo valor para $\mathrm{Cu}$, cujos teores (3,7 a 812,5 ppm) são, nas outras amostras, sistematicamente superiores aos de Mo. As razões $\mathrm{Au} / \mathrm{Ag}$ variam de 0,05 a 5,0, com cerca de dois terços dos valores acima da unidade e média de 1,7.

A relação entre $\mathrm{Au}$ e $\mathrm{Cu}, \mathrm{Pb}$ ou $\mathrm{Zn}$ (Figuras 9A a 9C) esboça certa linearidade, em especial nos diagramas $\mathrm{Au} \times \mathrm{Cu}$ e $\mathrm{Au} \times \mathrm{Pb}$, a qual, entretanto, torna-se inexpressiva se as amostras TOC-24-18 e TOC-24-37 forem desconsideradas. $\mathrm{Na}$ verdade não há relação definida entre o $\mathrm{Au}$ e aqueles metais-base e o que se observa é a distribuição aleatória dos teores de $\mathrm{Au}$, desde $<0,5 \mathrm{ppb}$ até cerca de $9 \mathrm{ppm}$, dentro do estreito intervalo entre $3 \mathrm{ppm}$ e $50 \mathrm{ppm}$ de $\mathrm{Cu}, \mathrm{Pb}$ ou $\mathrm{Zn}$, no qual estão representadas de 75 a $85 \%$ das amostras analisadas. Com relação à $\mathrm{Ag}$, o $\mathrm{Au}$ exibe notável comportamento linear (Figura 9D), observando-se, ademais, que esta linearidade é mais evidente com as amostras da variedade salame, a qual também registra, em geral, os mais elevados conteúdos destes dois metais preciosos. Embora não tenha sido identificada neste trabalho, hessita é mencionada em relatórios internos das empresas com ocorrência muito local (Mello, 2007). Por outro lado, a relação do Au com As é evidentemente fortuita (Figura 9E), sendo registrada ampla variação dos valores de As, a maioria entre 1 ppm e 13,4 ppm. A correlação do $\mathrm{Au}$ com Bi e Mo (Figuras 9F e 9G) é discretamente positiva, porém se observa certa dispersão dos pontos, notadamente daqueles que representam os conteúdos de Mo. Os teores de Bi são normalmente abaixo de $1 \mathrm{ppm}$, se bem que em uma amostra da variedade smoky (TOC-48-19) alcance quase $23 \mathrm{ppm}$.

\section{Isótopos de C e O em calcita}

A calcita venular, que foi analisada isotopicamente, pertence ao estágio da carbonatação e é, portanto, posterior à mineralização principal. As 11 amostras selecionadas forneceram valores de $\delta^{13} \mathrm{C}_{\mathrm{PDB}}$ que variam de $-3,45$ a $-0,64 \%$ o (Tabela 3 e Figura 10B) ou, se excluídas duas amostras, dentro do estreito intervalo de $-3,45$ a $-2,29 \%$, indicando reservatório homogêneo para o carbono. Os valores de $\delta^{18} \mathrm{O}_{\text {sMow }}$ são mais variáveis e cobrem a faixa de $+3,91$ a $+14,10 \%$ o (Figura 10A), refletindo, talvez, mais de uma fonte.

Estimativas de temperatura com base no geotermômetro da clorita (Cathelineau, 1988) indicam que a alteração hidrotermal no paleossistema Tocantinzinho ocorreu entre 315 e $275^{\circ} \mathrm{C}$ (Santiago, 2012). Tendo em vista que alguma clorita também foi coprecipitada com a calcita e assumindo-se $300^{\circ} \mathrm{C}$ como uma temperatura representativa da carbonatação, foram calculados os valores de $\delta^{18} \mathrm{O}_{\text {Smow }}$ para o fluido, de acordo com a equação $1000 \ln \alpha_{\text {calcita-ǵgua }}=-3,39+2,78\left(10^{6} / \mathrm{T}^{2}\right)$ definida para o fracionamento isotópico entre calcita e água (O'Neil, Clayton, Mayeda, 1969), os quais acusaram, exceto para um único valor negativo $(-1,67 \%)$, variação de $+0,39$ a $+8,52 \%$ (Tabela 3, Figura 10C).

\section{DISCUSSÕES}

A intrusão Tocantinzinho é constituída por várias fácies, sendo dominantes as rochas sieno e monzograníticas. Esta intrusão é muito similar, em termos geológicos e geoquímicos, ao granito São Jorge Antigo, localizado a cerca de $100 \mathrm{~km}$ a SE, nos arredores de Vila Riozinho, e originalmente descrito e datado por Lamarão et al. (2002). As idades de cristalização determinadas em cristais de zircão extraídos do granito São Jorge Antigo (1981 \pm 2 Ma e $1983 \pm 8 \mathrm{Ma})$ e de granitos porfiríticos a ele associados (1987 \pm 3 Ma e $1982 \pm 3$ Ma, Lamarão et al., 2008) são, dentro da faixa de erro, idênticas à obtida neste trabalho para o granito Tocantinzinho (1982 $\pm 8 \mathrm{Ma})$. As idades mais antigas (1999 e $2094 \mathrm{Ma}$ ) encontradas para este granito podem corresponder a xenocristais que foram incorporados ao magma a partir de unidades mais antigas (por exemplo o Complexo Cuiú-Cuiú e o Grupo Jacareacanga), e interpretadas como idades herdadas. 
Tabela 2. Dados químicos (rocha total) de alguns elementos traço para as variedades salame e smoky do depósito Tocantinzinho.

\begin{tabular}{|c|c|c|c|c|c|c|c|c|c|c|c|c|}
\hline $\begin{array}{l}\text { Amostras } \\
\text { Elementos }\end{array}$ & $\begin{array}{c}\text { Variedade } \\
\text { de rocha }\end{array}$ & $\mathrm{Au}$ & $\mathrm{Ag}$ & As & $\mathrm{Bi}$ & Mo & $\mathrm{Cu}$ & $\mathrm{Pb}$ & $\mathrm{Zn}$ & $\mathrm{Sn}$ & $\mathrm{Nb}$ & $\mathrm{Ta}$ \\
\hline TOC-24-02 & Salame & 5 & $<0,1$ & $<0,5$ & $<0,1$ & 0,3 & 4,8 & 2,9 & 8 & 1 & 12,0 & 0,9 \\
\hline TOC-24-04 & Salame & 2,2 & $<0,1$ & 0,6 & 0,3 & 0,2 & 6 & 2,9 & 61 & 1 & 5,9 & 0,5 \\
\hline TOC-24-10 & Salame & 1,1 & $<0,1$ & 0,8 & 0,1 & 1 & 4,7 & 3,9 & 18 & 3 & 13,2 & 1,3 \\
\hline TOC-24-16 & Smoky & 39 & 0,3 & 3,7 & 0,3 & 0,5 & 6,9 & 38,8 & 46 & 3 & 13,0 & 1,0 \\
\hline TOC-24-18 & Salame & 38.133 & 8,5 & 5,6 & 1,1 & 2,2 & 812,5 & 450,6 & 844 & 2 & 15,8 & 1,3 \\
\hline TOC-24-19 & Smoky & 45,6 & 0,2 & 1,1 & 0,3 & 0,2 & 3,3 & 19,8 & 12 & $<1$ & 13,2 & 0,7 \\
\hline TOC-24-23 & Smoky & 133,6 & 0,1 & 7,8 & 0,3 & 1,2 & 11,2 & 35 & 26 & 3 & 15,3 & 1,2 \\
\hline TOC-24-24 & Salame & 134,4 & 0,2 & 2,7 & 0,3 & 0,5 & 6,7 & 16,6 & 11 & 1 & 15,6 & 1,4 \\
\hline TOC-24-25 & Smoky & 474,1 & 0,3 & 13,2 & 0,2 & 0,3 & 11,2 & 20,8 & 22 & 3 & 15,2 & 1,1 \\
\hline TOC-24-26 & Salame & 1.203 & 0,4 & 1,5 & $<0,1$ & 0,4 & 4,9 & 2,1 & 9 & 1 & 11,3 & 1,2 \\
\hline TOC-24-27 & Smoky & 306,5 & 0,3 & 3,8 & 0,4 & 0,9 & 12,5 & 274,7 & 24 & 4 & 15,2 & 1,1 \\
\hline TOC-24-30 & Smoky & 463,1 & 0,5 & 2,1 & 0,4 & 0,3 & 40,9 & 42,4 & 44 & 3 & 15,7 & 1,2 \\
\hline TOC-24-37 & Salame & $13.033,7$ & 3,4 & 10,3 & 2,5 & 3 & 367 & 142,6 & 102 & 2 & 12,7 & 1,1 \\
\hline TOC-24-38 & Smoky & 3,5 & $<0,1$ & 2,3 & 0,5 & 0,5 & 5,8 & 3,3 & 25 & 3 & 14,3 & 1,2 \\
\hline TOC-24-39 & Salame & 175,8 & 0,3 & 2,9 & 0,4 & 0,5 & 15,8 & 33,2 & 32 & 2 & 11,6 & 1,0 \\
\hline TOC-24-44 & Smoky & $8.623,8$ & 1,7 & 7,6 & 0,5 & 1 & 9,1 & 66,1 & 15 & 5 & 16,3 & 1,4 \\
\hline TOC-24-54 & Salame & 4,1 & $<0,1$ & 1 & $<0,1$ & 3,6 & 6,1 & 6,8 & 75 & 1 & 8,5 & 0,6 \\
\hline TOC-27-07 & Smoky & 771,8 & 0,4 & 13,4 & 0,3 & 0,8 & 6,7 & 22,7 & 24 & 1 & 9,3 & 0,6 \\
\hline TOC-48-02 & Salame & 129,1 & $<0,1$ & 4,2 & 0,1 & 1,3 & 5,7 & 17,5 & 20 & 2 & 11,5 & 0,9 \\
\hline TOC-48-04A & Salame & $2.061,3$ & 1,1 & 6 & 0,8 & 3 & 22,9 & 95,6 & 15 & 3 & 19,6 & 1,5 \\
\hline TOC-48-04B & Smoky & 19,9 & 0,2 & 0,7 & 0,3 & 0,7 & 23,8 & 30,9 & 54 & 4 & 21,4 & 1,7 \\
\hline TOC-48-09 & Salame & 86,9 & $<0,1$ & 2,7 & 0,7 & 1,7 & 25,1 & 6,5 & 18 & 2 & 12,5 & 1,0 \\
\hline TOC-48-10A & Salame & 489,9 & 0,4 & 6 & 0,8 & 3 & 57,1 & 16 & 15 & 2 & 13,2 & 1,0 \\
\hline TOC-48-10B & Salame & $4.774,8$ & 1,6 & 3,8 & 0,4 & 0,9 & 87,3 & 11,6 & 24 & 2 & 13,5 & 1,1 \\
\hline TOC-48-19 & Smoky & 18,7 & 0,2 & 0,7 & 22,7 & 0,2 & 30,4 & 3,7 & 196 & 4 & 21,2 & 0,7 \\
\hline TOC-57-02 & Smoky & $<0,5$ & $<0,1$ & $<0,5$ & 1,3 & 0,1 & 1,9 & 1,5 & 22 & 3 & 6,4 & 0,3 \\
\hline TOC-57-04 & Smoky & $2.722,2$ & 1,2 & 8,9 & 1,3 & 1,3 & 18,4 & 67,7 & 21 & 2 & 11,3 & 1,1 \\
\hline TOC-97A-05 & Salame & 161,9 & 0,8 & 1,4 & 0,3 & 23,8 & 24,1 & 15,1 & 16 & 4 & 16,9 & 1,4 \\
\hline TOC-102B-03 & Smoky & 547 & 0,2 & 5,6 & $<0,1$ & 0,5 & 13,5 & 14,5 & 5 & 2 & 11,0 & 0,8 \\
\hline TOC-102B-04 & Smoky & 293 & 0,1 & 5,1 & 0,2 & 1,6 & 11,8 & 9,7 & 20 & 4 & 21,2 & 1,8 \\
\hline TOC-102B-17 & Smoky & 626,9 & 0,6 & 4,4 & 0,2 & 1,9 & 19 & 49,1 & 25 & 2 & 16,8 & 1,3 \\
\hline TOC-139-02 & Salame & $8.596,8$ & 2,2 & 0,6 & 2,3 & 1,5 & 18 & 9,2 & 35 & 3 & 17,1 & 1,4 \\
\hline TOC-142-01 & Salame & $1.889,2$ & 1,4 & 1,7 & 0,5 & 2,6 & 43,9 & 41 & 22 & 4 & 14,5 & 1,0 \\
\hline TOC-142-02 & Salame & 315,6 & 0,3 & 3,3 & 0,2 & 0,6 & 22,7 & 47,4 & 34 & 2 & 12,2 & 0,8 \\
\hline TOC-142-03 & Salame & 129,8 & 0,3 & 3,3 & 0,3 & 0,6 & 13,6 & 36,9 & 16 & 2 & 12,2 & 0,9 \\
\hline TOC-142-04 & Smoky & 3,1 & $<0,1$ & 0,5 & $<0,1$ & 0,3 & 6,2 & 20,7 & 27 & 2 & 12,6 & 0,9 \\
\hline TOC-174A-01 & Salame & 7,2 & $<0,1$ & $<0,5$ & $<0,1$ & 1,4 & 2,8 & 1,9 & 44 & 5 & 14,8 & 1,1 \\
\hline TOC-174A-03 & Smoky & 7,2 & $<0,1$ & $<0,5$ & $<0,1$ & 0,2 & 1,7 & 1,7 & 20 & 3 & 16,2 & 1,1 \\
\hline TOC-174A-04 & Smoky & 57,6 & $<0,1$ & $<0,5$ & 0,8 & 0,3 & 6,7 & 1,7 & 54 & 4 & 15,8 & 1,2 \\
\hline TOC-174A-08 & Smoky & 19,5 & $<0,1$ & $<0,5$ & 0,3 & 0,2 & 13,4 & 1,7 & 18 & 1 & 7,0 & 0,6 \\
\hline TOC-175-04 & Salame & 5 & $<0,1$ & $<0,5$ & $<0,1$ & 0,4 & 2,9 & 16 & 43 & 3 & 21,3 & 1,6 \\
\hline TOC-177-05 & Salame & 4,8 & 0,1 & $<0,5$ & 0,2 & 0,7 & 1,8 & 25,1 & 98 & 1 & 20,4 & 1,0 \\
\hline
\end{tabular}



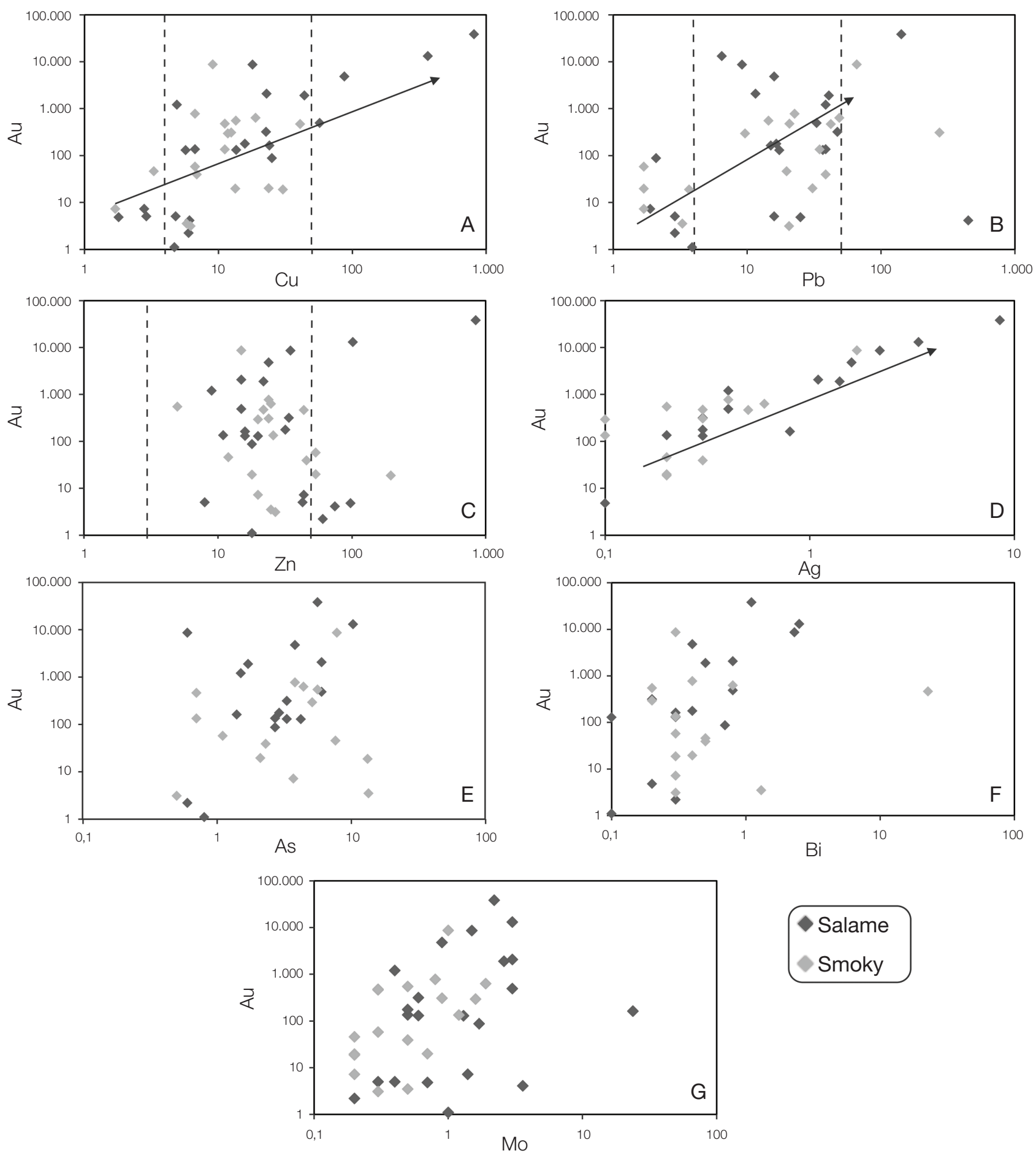

Figura 9. Diagramas de variação dos teores de Au em relação a metais e semimetais selecionados em amostras das variedades salame e smoky. (A) Au x Cu; (B) Au x Pb; (C) Au x Pb; (D) Au x Ag; (E) Au x As; (F) Au x Bi; (G) Au x Mo. Não constam os valores abaixo do limite de detecção.

Com base em dados geológicos, geoquímicos, petrográficos e geocronológicos disponíveis acerca do granito Tocantinzinho, pode-se afirmar que ele provavelmente representa uma das manifestações magmáticas precoces da suíte intrusiva Creporizão (1980 a 1957 Ma), o que permite posicioná-lo no final do ciclo orogenético Mundurucus durante intenso período de magmatismo cálcico-alcalino na PAT, quando se alojaram plútons graníticos que não foram 


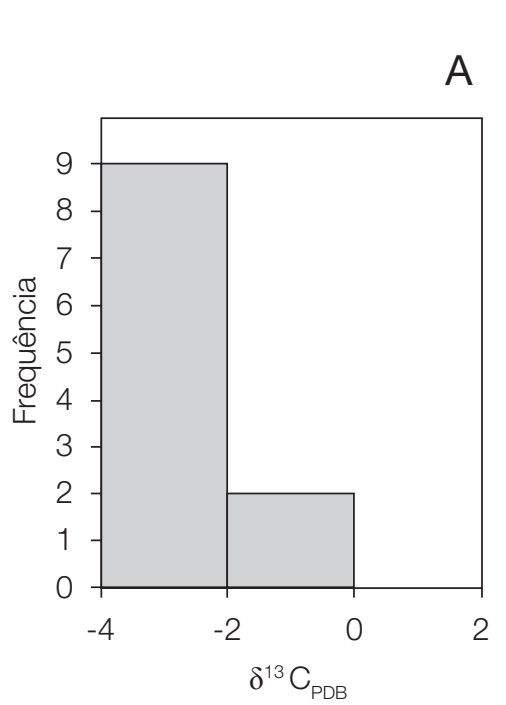

\section{CALCITA}

\section{$A$}

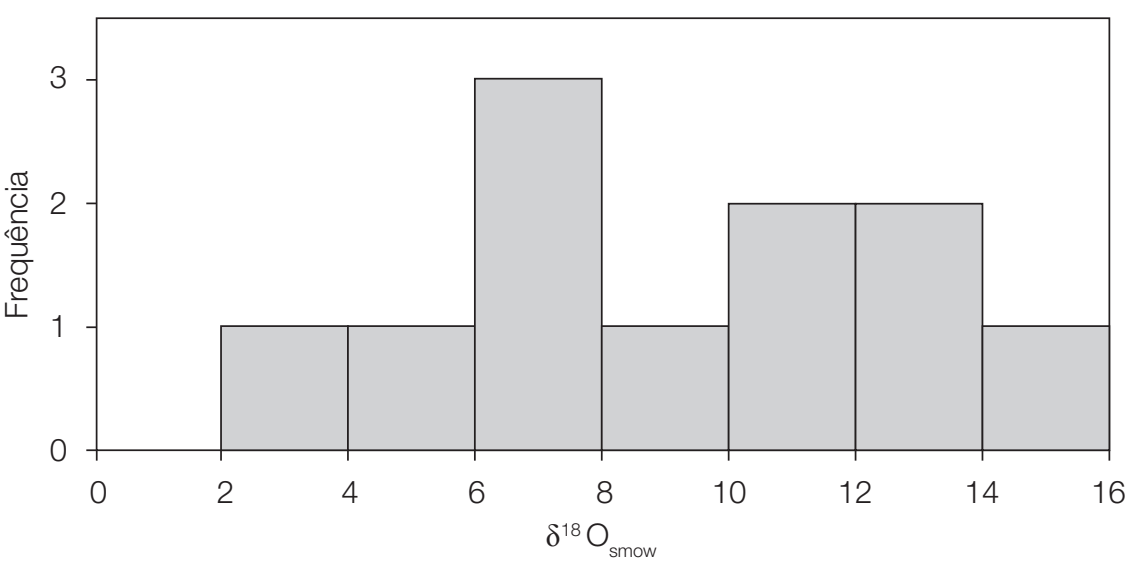

FLUIDO

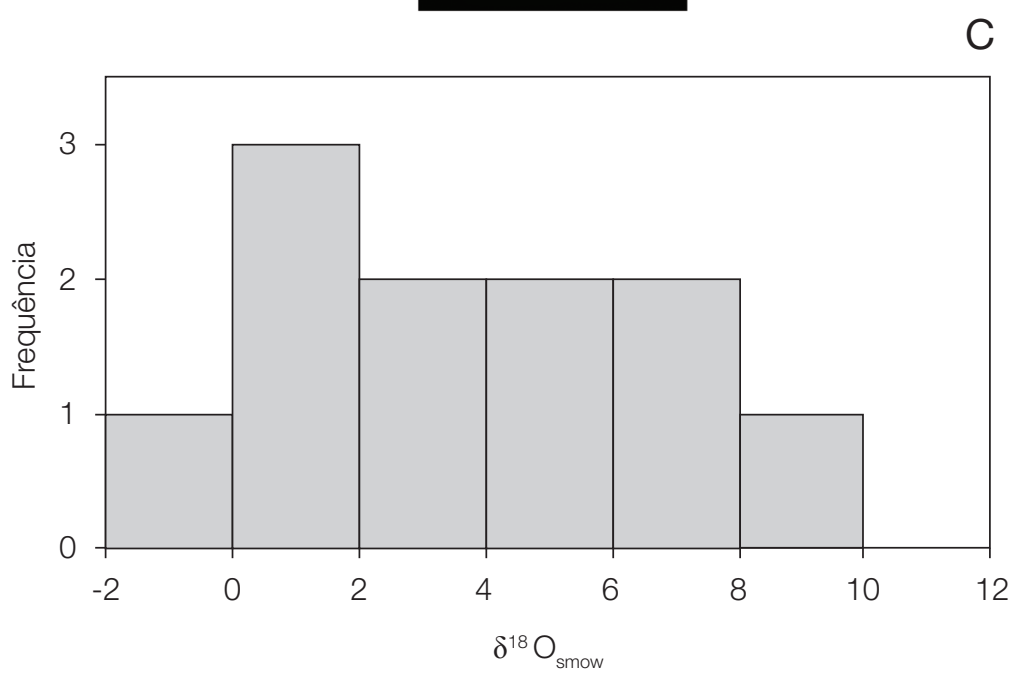

Figura 10. Histogramas de frequência para $\delta^{13} \mathrm{C}_{\mathrm{PDB}} \%(\mathrm{~A})$ e $\delta^{18} \mathrm{O}_{\mathrm{SMOW}} \%$ 。 $(\mathrm{B})$ obtidos em calcita presente em vênulas do depósito Tocantinzinho e de $\delta^{18} \mathrm{O}_{\text {SMow }} \%$ do fluido (C) em equilíbrio com a calcita e calculado a $\mathrm{T}=300^{\circ} \mathrm{C}$.

submetidos à deformação dúctil. Um exemplo é o próprio granito São Jorge Antigo e o Monzogranito Jamanxim (1996 \pm 4 Ma; Santos et al., 2004).

A pouca abundância de produtos hidrotermais, excepcionalmente alcançando $30 \%$, indica que a alteração ocorreu sob baixas razões fluido:rocha, dela tendo resultado as variedades salame e smoky, cujas similaridades texturais e composicionais são fortemente sugestivas de que são oriundas do mesmo protólito, sujeito, entretanto, a diferentes processos de alteração. A variedade salame foi um dos produtos da microclinização, que marca o primeiro estágio da principal alteração hidrotermal a qual o granito Tocantinzinho foi submetido. A temperaturas moderadas $\left(\sim 300^{\circ} \mathrm{C}\right)$, os fluidos eram suficientemente ácidos para destruir os minerais primários, notadamente a biotita e o plagioclásio, de que resultaram clorita e fengita como importantes produtos da alteração. As reações irreversíveis que controlaram essas mudanças mineralógicas liberaram sílica (por exemplo biotita $+\mathrm{H}^{+}+\mathrm{H}_{2} \mathrm{O}=$ clorita $+\mathrm{K}^{+}+\mathrm{H}_{4} \mathrm{SiO}_{4}$ ), a qual foi, posteriormente, precipitada como quartzo não só na massa rochosa como também em planos de fratura, caracterizando o processo de silicificação. Nos estágios finais da história hidrotermal, calcita foi estabilizada, com ocorrência mais comum em vênulas. É muito provável que o $\mathrm{Ca}$ tenha sido derivado principalmente da decomposição do plagioclásio, tanto do granito quanto dos andesitos, e as espécies de carbonato provenientes de fluidos aquocarbônicos presentes no sistema Tocantinzinho, como evidenciado por estudo de inclusões fluidas contidas em cristais de 
quartzo (Queiroz e Villas, 2012). Esses fluidos são, muito provavelmente, de origem magmática, a favor de que testemunham os valores positivos de $\delta^{18} \mathrm{O}_{\text {smow }}$ para o fluido responsável pelo estágio de carbonatação (Figura 10C), bem como os de $\delta^{13} \mathrm{C}_{\mathrm{PDB}}$ da calcita, entre -4 e $-2 \%$ (Figura $10 \mathrm{~A}$ ). No diagrama $\delta^{13} \mathrm{C}_{\mathrm{PDB}} \times \delta^{18} \mathrm{O}_{\text {SMOw }}$ (Figura 11), a maioria das amostras se distribui na interseção dos campos dos carbonatitos e dos calcários paleoproterozoicos. Como não há registro desses calcários na PAT, a fonte do C deve estar relacio nada a reservatórios magmáticos profundos, representados naquele diagrama pelos carbonatitos. Algumas amostras afastam-se do campo desses reservatórios por conta dos menores valores de $\delta^{18} \mathrm{O}_{\text {smow }}(<7 \%)$, os quais podem indicar re-equilíbrio isotópico ou contribuições de outras fontes, não necessariamente magmáticas.

A brechação antecedeu a mineralização, porém quando os fluidos mineralizantes passaram a migrar, as porções brechadas já haviam sido seladas, de sorte que elas permaneceram estéreis. $\mathrm{O}$ selamento, entretanto, tornou o granito novamente apto à ruptura, o que veio a ocorrer gerando fraturas preferencialmente nas direções $\mathrm{N} 20-30^{\circ} \mathrm{E}$ e $\mathrm{N} 70-80^{\circ} \mathrm{E}$. Foi por essas fraturas que os fluidos mineralizantes então percolaram, vindo a formar as vênulas enriquecidas em $\mathrm{Au}$ e sulfetos. Aparentemente, as rochas graníticas do corpo Tocantinzinho serviram apenas de hospedeiras ao minério aurífero, tendo os fluidos mineralizadores provavelmente originado de atividade magmática subsequente, porém ainda indefinida. Em outras palavras, levanta-se a possibilidade de os fluidos mineralizantes serem de fontes externas ao granito Tocantinzinho. A propósito, Hippertt (2012) aventa a hipótese de esses fluidos estarem relacionados à cristalização de granitos da Suíte Intrusiva Maloquinha (1,87 Ga), cujo magma, segundo Figueiredo (1999), apud

Tabela 3. Composição isotópica do oxigênio $\left(\delta \mathrm{O}^{18}\right)$ e carbono $\left(\delta \mathrm{C}^{13}\right)$ da calcita venular e do oxigênio do fluido do estágio de carbonatação a $300^{\circ} \mathrm{C}$ em relação aos padrões Standard Mean Ocean Water e Peedee Formation Belemnite.

\begin{tabular}{lcccc}
\hline \multirow{2}{*}{ Amostras } & \multicolumn{3}{c}{ Calcita (\%o) } & Fluido (\%o) \\
\cline { 2 - 5 } & $\delta \mathbf{C}^{13}{ }_{\text {PDB }}$ & $\delta \mathbf{O}^{18}{ }_{\text {PDB }}$ & $\delta \mathbf{O}^{18}{ }_{\text {smow }}$ & $\delta \mathbf{O}^{18}$ smow \\
\hline $008-89$ & $-0,64$ & $-23,12$ & 7,03 & $-1,45$ \\
$009-97$ & $-2,29$ & $-17,15$ & 13,19 & $-7,61$ \\
$009-98$ & $-2,37$ & $-26,15$ & 3,91 & 1,67 \\
$010-97$ & $-2,36$ & $-18,8$ & 11,48 & $-5,90$ \\
$010-98$ & $-1,56$ & $-24,15$ & 5,97 & $-0,39$ \\
$012-102$ & $-2,32$ & $-17,99$ & 12,31 & $-6,73$ \\
$13-97$ & $-3,45$ & $-16,26$ & 14,1 & $-8,52$ \\
$16-102$ & $-2,3$ & $-22,53$ & 7,64 & $-2,06$ \\
$21-98$ & $-2,44$ & $-20,79$ & 9,43 & $-3,85$ \\
$35-24$ & $-3,09$ & $-19,99$ & 10,24 & $-4,66$ \\
$49-24$ & $-2,42$ & $-23,23$ & 6,91 & $-1,33$ \\
\hline
\end{tabular}

\%: per mil; PDB: Peedee Formation Belemnite; SMOW: Standard Mean Ocean Water.
Lamarão et al. (2002), era pouco oxidado, próximo ao tampão NNO, o que certamente imporia alguma restrição à solubilidade do $\mathrm{Cu}$, Mo e, provavelmente, também do $\mathrm{Pb}, \mathrm{Zn}, \mathrm{Ag}, \mathrm{Bi}$ e As, mais fortemente particionados para as soluções aquosas exsolvidas de magmas oxidados e pouco fracionados, como tão bem documentado na faixa móvel Lachlan, na Austrália (Blevin e Chappell, 1992). Considerando os, em geral, baixos teores destes elementos nas rochas alteradas do granito Tocantinzinho, fluidos pouco oxidados podem ter sido responsáveis pelo minério aurífero nele hospedado. Por seu turno, a solubilidade do Au é menos influenciada pelas condições redox do magma do que $\mathrm{Cu}$ ou $\mathrm{Mo}$, tanto que, mais comuns em granitos oxidados, concentrações hidrotermais de Au também ocorrem associadas a granitos reduzidos tipo I (Sillitoe, 1996; Thompson et al., 1999; Rowins, 2000). O ouro poderia ter sido transportado na forma de complexos sulfetados, os quais, ao se desestabilizarem, levaram à precipitação do ouro em íntima associação com a pirita. Temperaturas inferiores a $350^{\circ} \mathrm{C}$ foram prevalentes no sistema hidrotermal Tocantinzinho e devem ter favorecido a formação daqueles complexos, particularmente os de bissulfetos $\mathrm{HAu}(\mathrm{HS})_{2}^{\circ}$ e $\mathrm{Au}(\mathrm{HS})_{2}^{-}$(Hayashi e Ohmoto, 1991; Seward e Barnes, 1997).

A falta de correlação positiva do $\mathrm{Au}$ com $\mathrm{Cu}, \mathrm{Pb}$ ou Zn mostra que calcopirita, galena e esfalerita não são os principais carreadores de $\mathrm{Au}$. Porém, como quanto maior a quantidade de sulfetos maiores são os teores de Au, fica reforçada a hipótese de que este metal está preferencialmente contido na pirita.

Dos quatro tipos de depósitos auríferos que têm sido descritos na PAT, o tipo epitermal é o que menos se adequa ao Tocantinzinho, haja vista as marcantes diferenças quanto ao ambiente geológico, rochas hospedeiras, alteração hidrotermal, nível crustal de formação e minerais de minério. Com relação aos sistemas porfiríticos, tanto

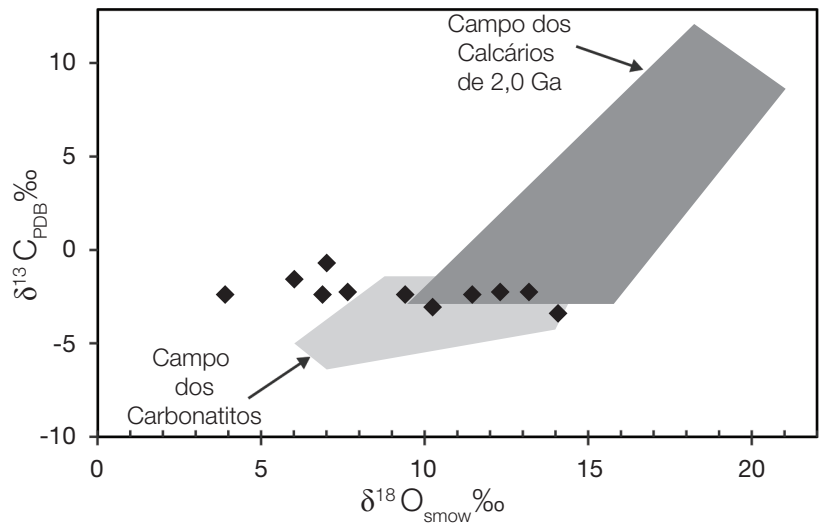

Figura 11. Diagrama $\delta^{13} \mathrm{C}_{\mathrm{PDB}}$ vS. $\delta^{18} \mathrm{O}_{\mathrm{SMOW}}$ em \%o para reservatórios naturais de carbonato (baseado em Rollinson, 1993). Os losangos referem-se à calcita do depósito Tocantinzinho. 
oxidados quanto reduzidos, há algumas semelhanças. Os clássicos depósitos porfiríticos de $\mathrm{Cu}-\mathrm{Au}$ (Seedorfe et al., 2005; Sillitoe, 2010), porém, ocorrem em rochas menos evoluídas de composição cálcio-alcalina, derivadas, em geral, de magmas oxidados que se alojaram a profundidades rasas $(<3 \mathrm{~km})$. As texturas primárias dessas rochas, várias delas representativas da fácies porfirítica, são, via de regra, severamente destruídas pela alteração hidrotermal, a qual produz abundante magnetita, hematita e anidrita/barita. Em relação aos depósitos porfiríticos de $\mathrm{Cu}-\mathrm{Au}$ reduzidos, há muitas similaridades com os congêneres oxidados, porém eles ocorrem em granitos tipo I reduzidos, os quais contêm pirrotita e baixos teores de $\mathrm{Cu}$ (Rowins, 2000; Smith et al., 2012). Independentemente do estado redox, os fluidos são dominantemente aquosos, salinos e de origem magmática, e muitas destas características não são observadas no depósito Tocantinzinho.

Com base em suas características gerais, ele pode ser descrito como um depósito aurífero relacionado à intrusão (intrusion-related gold deposit), satisfazendo a maioria dos critérios apontados na literatura (por exemplo em Sillitoe, 1991; Thompson et al., 1999; Lang et al., 2000; Lang e Baker, 2001), a saber: caráter metaluminoso dos granitoides; estado de oxidação próximo do limite entre as séries da ilmenita e magnetita; presença de fluidos hidrotermais aquocarbônicos; associação do $\mathrm{Au}$ com Bi, As, Mo; baixas concentrações de metais-base; rochas hospedeiras fraca a moderadamente alteradas; baixo teor de sulfetos $(<5 \%)$; e contexto tectônico de proximidade a limites convergentes de placas, onde se alojaram contemporaneamente intrusões de composição alcalina, cálcio-alcalina metaluminosa e peraluminosa. Contudo, ainda não há dados suficientes para afirmar se os fluidos mineralizantes são oriundos do próprio granito Tocantinzinho ou de outra fonte, a exemplo da Suíte Intrusiva Maloquinha, como sugerido por Hippertt (2012), caso em que o Tocantinzinho seria posicionado distalmente em relação ao centro magmático que gerou os fluidos mineralizantes.

A inclusão deste depósito na categoria dos relacionados a intrusões foi proposta inicialmente por Mello (2007) e, mais tarde, referendada por Juras et al. (2011). Os novos dados aqui apresentados corroboram essa interpretação. Contudo, para consolidá-la ou eleger outro modelo genético, será necessário aprofundar as investigações de campo, datar a mineralização e obter dados termodinâmicos e isotópicos para os fluidos mineralizadores, dentre outros requisitos.

Deve-se também considerar que, especialmente nos casos em que o alojamento do granito foi controlado por zonas de cisalhamento, a distinção entre depósitos auríferos orogênicos e relacionados a intrusões exige análise muito criteriosa, haja vista eles convergirem geologicamente em muitos aspectos (Sillitoe e Thompson, 1998).
No que se refere ao depósito Tocantinzinho, a falta de alguns dados críticos posterga essa análise para quando eles se tornarem disponíveis.

\section{CONCLUSÕES}

O granito Tocantinzinho, hospedeiro do depósito aurífero homônimo, foi datado em $1982 \pm 8$ Ma pelo método de evaporação de $\mathrm{Pb}$ em zircão e interpretado como uma manifestação magmática precoce da suíte intrusiva Creporizão, que se instalou na Província Tapajós nos estágios finais da orogênese Mundurucus. É essencialmente isotrópico e nele são dominantes as rochas sieno e monzograníticas, que mostram grau de alteração fraco a moderado, com microclinização, cloritização, sericitização, silicificação e carbonatação sendo os mais importantes tipos de alteração hidrotermal. A mineralização se manifesta principalmente em vênulas de quartzo, de direções preferenciais N20$30^{\circ} \mathrm{E}$ e $\mathrm{N} 70-80^{\circ} \mathrm{E}$, e com quantidades variáveis de clorita, fengita e sulfetos, embora os sulfetos de metais-base $(\mathrm{Cu}$, $\mathrm{Pb}$ e $\mathrm{Zn}$ ) ocorram somente naquelas de formação mais tardia. Os maiores teores de $\mathrm{Au}$ coincidem com as porções mais enriquecidas em sulfetos. Como não há relação direta com as concentrações de $\mathrm{Pb}$ e $\mathrm{Zn}$, pôde-se deduzir que o $\mathrm{Au}$ está principalmente contido na pirita. As razões $\mathrm{Au} /$ Ag são muito variáveis ( 0,05 a 5), entretanto, na maioria das amostras (dois terços), elas acusam valores acima de 1. Entre estes dois metais preciosos a correlação é linear e positiva, o mesmo não se constatando entre $\mathrm{Au}$ e $\mathrm{As}$, $\mathrm{Bi}$ ou Mo, cujas relações são aleatórias. Os conteúdos destes três últimos elementos são baixos, embora em algumas amostras possam ser considerados anômalos.

Dados isotópicos revelam valores de $\delta^{13} \mathrm{C}_{\mathrm{PDB}}$ homogêneos e indicam que o carbono da calcita do estágio de carbonatação é oriundo de fontes crustais profundas, muito provavelmente mantélicas. Os valores de $\delta^{18} \mathrm{O}_{\text {SMOW }}$, por sua vez, são bem mais variáveis e denunciam, além da assinatura magmática, contribuição de outras fontes, que tornaram alguns deles relativamente mais enriquecidos em ${ }^{16} \mathrm{O}$. A composição isotópica dos fluidos hidrotermais $\left(\delta^{18} \mathrm{O}_{\text {smow }}\right)$, estimada para uma temperatura de $300^{\circ} \mathrm{C}$, prevalente durante a carbonatação, é dominantemente magmática, mas mostra modificações impostas pelo influxo de águas superficiais, provavelmente meteóricas.

Como a carbonatação foi o processo mais tardio da alteração hidrotermal do sistema Tocantinzinho, é muito provável que os fluidos responsáveis pela mineralização que a precedeu também tenham sido essencialmente magmáticos, conforme dados de $\delta \mathrm{C}^{13}{ }_{\mathrm{PDB}} \mathrm{da}$ calcita do estágio de carbonatação e $\delta \mathrm{O}^{18}{ }_{\text {SMOW }}$ do fluido hidrotermal. Não há ainda dados para afirmar qual a fonte desses fluidos, que podem estar associados a 
evento magmático granítico posterior ao alojamento do granito Tocantinzinho, o qual, nesse caso, teria servido apenas como hospedeiro do corpo mineralizado. Não obstante, evidências petrográficas, mineralógicas, geoquímicas e isotópicas das zonas alteradas e mineralizadas favorecem o enquadramento do depósito aurífero Tocantinzinho no tipo relacionado à intrusão (intrusion-related gold deposit).

\section{AGRADECIMENTOS}

Agradecemos à Brazauros Resources Corporation e a Unamgen Mineração e Metalurgia Ltda. pelo apoio logístico nos trabalhos de campo e cessão de testemunhos de sondagem; aos Drs. Alcides Nóbrega Sial, Marco Antonio Galarza Toro e Cláudio Nery Lamarão pela realização, respectivamente, dos trabalhos analíticos no Laboratório de Isótopos Estáveis da Universidade Federal de Pernambuco (Labise-UFPE), Laboratório de Geologia Isotópica da Universidade Federal do Pará (Iso-Pará-UFPA) e Laboratório de Microscopia Eletrônica de Varredura da Universidade Federal do Pará (LabMev-UFPA); ao Dr. Jean Michel Lafon, pela inestimável colaboração na interpretação dos dados geocronológicos; à Fundação de Amparo e Desenvolvimento da Pesquisa do Estado do Pará (FAPESPA) (Proc. 117/2008-Universal) e ao Instituto Nacional de Ciência e Tecnologia da Amazônia (Geociam) pelo apoio financeiro; e à Coordenação de Aperfeiçoamento de Pessoal de Nível Superior (CAPES) pela bolsa de mestrado concedida à autora Érika Suellen Barbosa Santiago.

\section{REFERÊNCIAS}

ALMEIDA, M. E.; BRITO, M. F. L.; FERREIRA, A. L.; MONTEIRO, M. A. S. Geologia e recursos minerais da Folha Mamãe Anã (SB.21-V-D). Estados do Amazonas e Pará: Nota explicativa. Brasília, CPRM, 2000. Escala 1:250.000. CD-ROM.

BLEVIN, P. L.; CHAPPELL, B. W. The role of magma sources, oxidation states and fractionation in determining the granite metallogeny of eastern Australia. Transactions of the Royal Society of Edinburgh: Earth Sciences, v. 83, p. 305-316, 1992.

CATHELINEAU, M. Cation site occupancy in chlorites and illites as a function of temperature. Clay Minerals, v. 23, p. 471-485, 1988.

CORRÊA SILVA, R. H. Caracterização de um sistema epitermal low-sulfidation (adularia-sericita) mineralizado em Au-Cu-Mo em vulcânicas paleoproterozóicas na Província Aurífera do Tapajós: implicações metalogenéticas e tectônicas. 2002. Dissertação (Mestrado) - Instituto de Geociências, Universidade de São Paulo, São Paulo.

COSTI, H. T.; DALL'AGNOL, R.; MOURA, C. A. V. Geology and $\mathrm{Pb}-\mathrm{Pb}$ geochronology of Paleoproterozoic volcanic and granitic rocks of Pitinga Province, Amazonian Craton, Northern Brazil. International Geology Reviews, v. 42, p. 832-849, 2000.

COUTINHO, M. G. N.; SANTOS, J. O. S.; FALLICK, A. E.; LAFON, J. M. Orogenic gold deposits in Tapajós Mineral Province, Amazon, Brazil. In: INTERNATIONAL GEOLOGICAL CONGRESS, 31, 2000. Rio de Janeiro. Anais... Rio de Janeiro: SBG, 2000.

DOE, B. R.; ZARTMAN, R. E. Plumbotectonics, the Phanerozoic. In: BARNES, H. L. (ed.) Geochemistry of hydrothermal ore deposits. New York: John Wiley \& Sons, 1979. p. 22-70.

FIGUEIREDO, M. A. B. M. Minerais óxidos de Fe $e$ Ti e susceptibilidade magnética em vulcânicas $e$ granitóides proterozóicos de vila Riozinho, província aurífera do Tapajós. 1999. 171 f. Dissertação (Mestrado) - Centro de Geociências, Universidade Federal do Pará, Belém.

GALARZA, M. A.; KRYMSKY, R. S.; ROLANDO, A. P. Datação de partículas de ouro nativo pelo método de evaporação de Pb. In: SIMPÓSIO DOS 40 ANOS DE GEOCRONOLOGIA NO BRASIL, 2004. São Paulo. Boletim de Resumos... São Paulo: Instituto de Geociências da USP, 2004. p. 35.

HAYASHI, K.; OHMOTO, H. Solubility of gold in $\mathrm{NaCl}$ - and $\mathrm{H}_{2} \mathrm{~S}$-bearing aqueous solutions at $250-350^{\circ} \mathrm{C}$. Geochimica et Cosmochimica Acta. v. 55, p. 2111-2126, 1991.

HIPPERT, J. Geologia, desenvolvimento e viabilidade econômica do Projeto Tocantinzinho, Província Aurífera do Tapajós, PA. In: SIMPÓSIO BRASILEIRO DE EXPLORAÇÃO MINERAL. 5., 2012, Ouro Preto. Anais eletrônicos... Ouro Preto: ADIMB, 2012. Disponível em: $<$ http://www.adimb.com.br/simexmin2012/wpcontent/ themes/simexmin/palestras/07tapajosxingu/VI_5_ Hippertt.pdf>. Acesso em: 26 out. 2012.

JACOBI, P. The discovery of epithermal Au-Cu-Mo proterozoic deposits in the Tapajós Province, Brazil. Revista Brasileira de Geociências. v. 29, p. 277-279, 1999. 
JULIANI, C.; CORRÊA SILVA, R. H.; MONTEIRO, L. V. S.; BETTENCOURT, J. S.; NUNES, C. M. D. The Batalha AuGranite system-Tapajós Province, Amazonian Craton, Brazil: hydrothermal alteration and regional implication. Precambrian Research. v. 119, p. 225-256, 2002.

JULIANI, C.; RYE, R. O.; NUNES, C. M. D.; SNEE, L. W.; SILVA, R. H. C.; MONTEIRO, L. V. S.; BETTENCOURT, J. S.; NEUMANN, R.; ALCOVER NETO, A. Paleoproterozoic high-sulfidation mineralization in the Tapajós gold province, Amazonian Craton, Brazil: geology, mineralogy, alunite argon age, and stable isotope constraints. Chemical Geology. v. 215, p. 95-125, 2005.

JULIANI, C.; MONTEIRO, L. V. S.; BETTENCOURT, J. S.; FERNANDES, C. M. D. Epithermal and porphyryrelated $\mathrm{Au}$ and base-metal mineralizations in the Paleoproterozoic Uatumã magmatism-Tapajós Gold Province, Amazonian Craton. In: INTERNATIONAL GEOLOLOGICAL CONGRESS, 33, 2008. General Proceedings..., IUGS, 2008. [CD-ROM].

JURAS, S.; GREGERSEN, S.; ALEXANDER, R. Technical report for the Tocantinzinho Gold Project, Brazil. Vancouver: Eldorado Gold Corporation. 2011. (Relatório Inédito).

KLEIN, E. L.; VASQUEZ, M. L; ROSA-COSTA, L. T. da; CARVALHO, J. M. de A. Geology of Paleoproterozoic gneissand granitoid-hosted gold mineralization in Southern Tapajós Gold Province, Amazonian Craton, Brazil. International Geology Reviews. v. 44, p. 544-558, 2002.

LAMARÃO, C. N.; DALL'AGNOL, R.; LAFON, J. M.; LIMA, E. F. Geology, geochemistry, and $\mathrm{Pb}-\mathrm{Pb}$ zircon geochronology of the Paleoproterozoic magmatism of Vila Riozinho, Tapajós Gold Province, Amazonian Craton, Brazil. Precambrian Research. v. 119, p. 189-223, 2002.

LAMARÃO, C. N.; DALL'AGNOL, R.; PIMENTEL, M. M. $\mathrm{Nd}$ isotopic composition of Paleoproterozoic volcanic rocks of Vila Riozinho: implications for the crustal evolution of the Tapajós gold province, Amazon Craton. Journal of South American Earth Sciences. v. 18, p. 277-292, 2005.

LAMARÃO, C. N.; SOUZA, K. S. DE; DALL'AGNOL, R.; GALARZA, M. A. Granitos pórfiros da região de Vila Riozinho, província aurífera do Tapajós: petrografia e geocronologia. Revista Brasileira de Geociências. v. 38, p. 533-543, 2008.

LANG, J. R.; BAKER, T.; HART, C. J. R.; MORTENSEN, J. K. An exploration model for intrusion-related gold systems. Society of Economic Geology Newsletter, v. 40, p. 6-15, 2000.

LANG, J. R.; BAKER, T. Intrusion-related gold systems: the present level of understanding. Mineralium Deposita. v. 36, p. 477-489, 2001.

MELLO, R. B. A preliminary assessment of the Tocantinzinho Gold Project, Tapajós Gold District, Pará State, Brazil - Three million tons/year scenario. Nova Lima: Brazauros Resources Corporation. 2007. (Relatório Inédito).

NOGUEIRA, A. C. R.; RICCOMINI, C.; SIAL, A. N.; MOURA, C. A. V.; TRINDADE R. I. F.; FAIRCHILD, T. R. Carbon and strontium isotopes fluctuations and paleoceanographic changes in the late Neoproterozoic Araras platform, southern Amazon Craton, Brazil. Chemical Geology. v. 237, p. 168-190, 2007.

NOTTO, S. Depósito do Palito: primeira mina de $\mathrm{Au}$ primário da Província Aurífera do Tapajós. In: SIMPÓSIO PROVÍNCIA AURÍFERA DO TAPAJÓS, 1, 2007. Memória..., Itaituba: ADIMB, 2007. [CD-ROM].

O’NEIL, J. R.; CLAYTON, R. N.; MAYEDA, T. Oxygen isotope fractionation in divalent metal carbonates. Journal of Chemical Physics. v. 51, p. 5547-5558, 1969.

QUEIROZ, J. S.; VILLAS, R. N. Estudo dos fluidos hidrotermais relacionados ao depósito Tocantinzinho, Província Aurífera do Tapajós, com base em inclusões fluidas In: CONGRESSO BRASILEIRO DE GEOLOGIA, 46, 2012, Santos. Anais eletrônicos... São Paulo: SBG, 2012. [CD-ROM].

ROLLINSON, H. R. Using geochemical data: evaluation, presentation, interpretation. Harlow: Longman, 1993. 352 p.

ROWINS, S. M. Reduced porphyry copper-gold deposits: a new variation on an old theme. Geology. v. 28, p. 491-494, 2000.

SANTIAGO, E. S. B. Rochas hospedeiras, alteração hidrotermal e avaliação do balanço geoquímico de massa do depósito aurífero Tocantinzinho, Província do Tapajós-PA. 2012. Dissertação (Mestrado) - Instituto de Geociências, Universidade Federal do Pará, Belém.

SANTOS, J. O. S.; HARTMANN, L. A.; GAUDETTE, H. E.; GROVES, D. I.; ALMEIDA, M. E.; MCNAUGHTON, N. J.; FLETCHER, I. R. A new understanding of the provinces of the Amazon Craton based on integration of field mapping and $\mathrm{U}-\mathrm{Pb}$ and $\mathrm{Sm}-\mathrm{Nd}$ geochronology. Gondwana Research. v. 3, p. 453-488, 2000. 
SANTOS, J. O. S.; GROVES, D. I.; HARTMANN, L. A.; MOURA, M. A., MCNAUGHTON, N. J. Gold deposits of the Tapajós and Alta Floresta Domains, TapajósParima orogenic belt, Amazon Craton, Brazil. Mineralium Deposita. v. 36, p. 453-488, 2001.

SANTOS, J. O. S.; VAN BREEMEN, O. T.; GROVES, D. I.; HARTMANN, L. A.; ALMEIDA, M. E.; MCNAUGHTON, N. J.; FLETCHER, I. R. Timing and evolution of multiple Paleoproterozoic magmatic arcs in the Tapajós Domain, Amazon Craton: constraints from SHRIMP and TIMS zircon, baddeleyite and titanite $\mathrm{U}-\mathrm{Pb}$ geochronology. Precambrian Research. v. 131, p. 73-109, 2004.

SEEDORFE, E.; DILLES, J. H.; PROFFETT JR., J. M.; EUNADI, M. T.; ZURCHER, L.; STAVAST, W. J. A.; JOHNSON, D. A.; BARTON, M. D. Porphyry deposits: characteristics and origin of hypogene features. In: HEDENQUIST, J. W.; THOMPSON, J. F. H.; GOLDFARB, R. J.; RICHARDS, J. P. (ed.) Economic geology 100th anniversary volume (1905-2005), Littleton: Society of Economic Geologists, 2005. p. 251-298.

SEWARD, T. M.; BARNES, H. L. Metal transport by hydrothermal ore fluids. In: BARNES, H. L. (ed.) Geochemistry of hydrothermal ore deposits. New York: John Wiley \& Sons, 1997. p. 435-486.

SILLITOE, R. H. Intrusion-related gold deposits. In: FOSTER, R. P. (ed.) Gold metallogeny and exploration. Glasgow: Blackie \& Son, 1991. p. 165-209.

SILLITOE, R. H. Granites and metal deposits. Episodes. v. 19, p. 126-133, 1996.
SILLITOE, R. H. Porphyry copper systems. Economic Geology, v. 105, p. 3-41, 2010.

SILLITOE, R.; THOMPSON, J. H. F. Intrusion-related vein gold deposits: types, tecto-magmatic settings and difficulties of distinction from orogenic gold deposits. Resource Geology, v. 48, p. 237-250, 1998.

SMITH, C. M.; CANIL, D.; ROWINS, S. M.; FRIEDMAN, R. Reduced granitic magmas in arc setting: the Catface porphyry $\mathrm{Cu}-\mathrm{Mo}$ deposit of the Paleogene Cascade arc. Lithos. v. 154, p. 361-373, 2012.

STACEY, J. S.; KRAMERS, J. D. Approximation of terrestrial lead isotopic evolution by a two stage model. Earth and Planetary Science Letters. v. 26, p. 207-221, 1975.

TASSINARI, C. C. G.; MACAMBIRA, M. J. B. A evolução tectônica do Cráton Amazônico. In: MANTESSONETO, V.; BARTORELLI, A.; CARNEIRO, C. D. R.; BRITO NEVES, B. B. (eds.). Geologia do Continente Sul-Americano: evolução da obra de Fernando Flávio Marques de Almeida. São Paulo: Beca, 2004. p. 471-485.

THOMPSON, J. F. H.; SILLITOE, R. H.; BAKER, T.; LANG, J. R.; MORTENSEN, J. K. Intrusion-related gold deposits associated with tungsten-tin provinces. Mineralium Deposita. v. 34, p. 323-334, 1999.

VASQUEZ, M. L.; RICCI, P. S. F.; KLEIN, E. L. Granitoides pós-colisionais da porção leste da Província Tapajós. In: KLEIN, E. L.; VASQUEZ, M. L.; ROSACOSTA, L. T. (org.) Contribuições à geologia da Amazônia. Belém: SBG, 2002. v. 3, p. 67-84. 